\title{
Evaluation of VCAM-1 and SPCAM-1 as biomarkers for the detection of hepatocellular carcinoma in patients with Hepatitis $\mathrm{C}$ virus
}

\author{
Tarek Abdel Sattar ${ }^{1}$, Amal Ahmed Mohamed ${ }^{2}$, Hoda G. Hegazy ${ }^{3}$, Wafaa Gh. Shousha ${ }^{4}$ \\ and Ahmed R. Ezzat ${ }^{3}$ \\ 1. Cardiothoracic surgery unit-Cairo University Hospitals, Kasr El-Ainy, Cairo Egypt. \\ 2. The National Hepatology and Tropical Medicine Research Institute, Cairo, Egypt. \\ 3. Zoology Department, Faculty of Science, Ain Shams University, Cairo, Egypt. \\ 4. Chemistry Department, Faculty of Science, Helwan University, Cairo, Egypt.
}

Received: July 30, 2020; Accepted: August 28, 2020; Available Online November 20, 2020

\begin{abstract}
Hepatocellular carcinoma (HCC), the third leading cause of cancer deaths worldwide. Early diagnosis of HCC remains a challenge and diagnosis is usually achieved by biomarkers, but up to date, there is not a perfect single biomarker for this tumor. The diagnostic and predictive abilities of the biomarkers are limited by the heterogeneous nature of the HCC and to improve the predicatively and sensitivity, combinations of biomarkers, or a panel of biomarker combinations and clinical parameters as well as laboratory test results, might be required The objective of the present study was to assess a combination of biomarkers that is reliable in the diagnose and the prognosis of HCV-related HCC. For this purpose, a group of biomarkers including two novel ones; the vascular adhesion molecule-1 (VCAM1) and soluble platelet endothelial cell adhesion molecule 1(sPECAM-1) were measured in Egyptian patients with chronic HCV and HCC. The ROC analyses were applied to evaluate the specificity and sensitivity of the biomarkers and come up with a recommendation for the employment of these markers to predict early development of hepatitis $C$ to hepatocellular carcinoma. In the present study, 120 individuals from the National Hepatology and Tropical Medicine Research Institute, enrolled during the period from September 2014 to March 2017, were divided into four major groups; the control group which comprised 20 individuals.HCV group comprising 50 patients with chronic hepatitis C genotype 4, HCC group comprising 25 patients with $\mathrm{HCC}$ without $\mathrm{HCV}$, and finally the $\mathrm{HCC}+\mathrm{HCV}$ group comprising 25 patients with proven chronic hepatitis $\mathrm{C}$ genotype 4 and hepatocellular carcinoma. All the study patients were subjected to laboratory investigations which included liver functions, oxidative stress, LDH, AFP, IL-10, IL-6, IL-8, TNF- $\alpha$, IFN- $\gamma$, Caspase-3, MCP-1, VCAM-1 and sPECAM-1, to predict early development of hepatitis $\mathrm{C}$ to hepatocellular carcinoma. The results suggested that there were significant differences in most of the liver functions, LDH, oxidative stress, IL-8, TNF- $\alpha$, MCP-1 and AFP between healthy individuals and the groups with the disease forms. There were no significant correlations between serum IL-6, IL-10, INF- $\gamma$, VCAM-1, sPECAM-1 and caspase-3 with HCV or HCC. The ROC curve analyses revealed that SPECAM-1 and SVCAM-1 were not sensitive biomarkers for HCC. AFP levels were highly specific, but insufficiently sensitive to detect HCC. Serum PECAM and serum VCAM were not sensitive indicators for HCC diagnosis because of their low discriminative power between groups. Consequently, they were passive with respect to their predictive power in the progression of HCV-related HCC development. In conclusion, relying on a single marker for the diagnosis of HCC is not possible by employing the nowadays widely used markers in diagnostic practice.
\end{abstract}

Keywords: Biomarkers - Diagnosis - Hepatitis C Virus - Hepatocellular Carcinoma -VCAMsPCAM-1 - Inflammatory Cytokines - ROC Analysis. 
Tarek Abdel Satter et al.

\section{INTRODUCTION}

Hepatocellular carcinoma (HCC) is a major worldwide health problem and represents the third most common cause of cancer-related death worldwide (Balogh et al., 2016). There is a considerable geographical variation in the incidence of HCC. In Egypt, up to $90 \%$ of recorded HCC cases were attributed to hepatitis $\mathrm{C}$ viral (HCV) infection. Approximately $14 \%$ of the population in Egypt is infected with $\mathrm{HCV}$. Studies of HCV progression to $\mathrm{HCC}$ are expected to provide new insights into the management of this increasingly significant health problem (Deuffic-Burban et al., 2006). Over the course of 20 years or more, $10 \%-30 \%$ of HCV carriers developed cirrhosis; patients with cirrhosis have an annual risk of $1 \%-2 \%$ for developing HCC (Di-Bisceglie et al., 2003).

Early diagnosis is crucial for improving the survival rate of HCC patients and remains a challenge due to the geographic and biological heterogeneity of the disease (Wang et al., 2013)and lack of consensus on how to best classify patients (Subramanian et al., 2013).

The development of reliable tumor markers that can detect $\mathrm{HCC}$ at earlier stages is essential. Predictive biomarkers are considered a key for the success of developing new drugs. The functions of tumor markers include screening for cancer, diagnosis, and prediction of the prognosis in therapeutic response the ideal biomarkers should be highly sensitive and specific for surveillance of high-risk populations and early detection of $\mathrm{HCC}$ and also be able to predict therapeutic outcome and provide a prognosis on survival.

Alpha-fetoprotein (AFP), along with radiology and pathology detection, is commonly used in the clinical early diagnosis of liver cancer. However, the specificity and sensitivity of AFP used in screening for liver cancer are not satisfactory. Concurrently, diagnosis is usually achieved by biomarkers, which can also help in prognosis and prediction. Furthermore, it might represent certain therapeutic interventions through some combinations of biomarkers (Lou et al., 2017). At present, the current understanding of HCC biomarkers is being carefully reviewed. Although the new advances in molecular biology have led to the identification of new tumor markers, yet more markers are required for effective early diagnosis and monitoring of the curative effects (Jie et al., 2013). New biomarkers of HCC have been identified using advanced genomic, proteomic, and metabolomics technologies. These are being developed not only for use in the diagnosis of HCC, but also in the prediction of patient and treatment outcomes and individualization of therapy. Some HCC biomarkers are currently used in surveillance to detect early stage HCCs and reduce mortality. Further studies are needed to determine whether the recently identified HCC biomarkers, most of them are only in phase 1 or 2 studies, can be used in clinical practice (Chaiteerakij et al., 2015).

Soluble vascular cell adhesion molecule-1 (VCAM-1), a member of the immunoglobulin superfamily, is expressed on various types of cells, including endothelial cells. . VCAM-1is released into the bloodstream by vascular endothelial activation mediated by proinflammatory cytokines (Diaz-Sanchez et al., 2013). This molecule plays an important role in providing attachment to the developing endothelium during angiogenesis (Byrne et al., 2000). Due to its angiogenic potency, elevated serum levels of VCAM-1 significantly correlate with tumor stage and the development of metastasis in neoplasms such as colorectal cancer, melanoma, 


\section{Evaluation of VCAM-1 and SPCAM-1 as biomarkers for the detection of Hepatocellular Carcinoma in patients with Hepatitis $\mathrm{C}$ virus}

leukemia and breast cancer (Hintermann and Christen, 2019). Furthermore, Diaz-Sanchez et al. (2013) reported that sVCAM-1 acts as a potential marker of hyperdynamic circulation, which is closely related to different stages of liver cirrhosis. Chronic hepatitis and cirrhosis are underlying liver conditions in most patients with HCC; therefore sVCAM-1 may represent a good candidate as a marker for the progression of both tumor and chronic liver disease. On the other hand, soluble platelet endothelial cell adhesion molecule1 PECAM-1 is systematically expressed on platelets, monocytes, neutrophils, NK and CD8 Tcells. The high expression exists in continuous endothelial cells, in cell-cell borders, but there is a weak expression on sinusoidal endothelial cells (Katz et al., 2004). PECAM-1 plays a presumed role in the inflammatory process and leukocyteendothelial interaction, especially in the transmigration of leukocytes through intercellular junctions. PECAM-1 is capable of mediating both hemophiliac adhesion and heterophilic binding to other molecules. Moreover, PECAM-1 has been implicated in cell survival, angiogenesis and affects activation and regulates the trafficking of integrins.PECAM-1 enhances T lymphocyte ability to bind to $\beta 1$ integrin substrates, such as VCAM-1 (Hintermann and Christen, 2019).

Serum cytokines important in inflammation and tumor immunity have been studied in HCC patients. Therefore, serum cytokine levels important for key inflammatory and tumor immunity pathways would differentiate $\mathrm{HCC}$ patients from cirrhotic patients without HCC. These cytokines would be predictive for overall prognosis of patients with HCC. Among all the cytokines evaluated, interleukin-8 appeared to have the greatest translational significance to $\mathrm{HCC}$ presence and was able to predict to overall prognosis (Welling et al., 2012). Recently, serum interleukin-6 (IL-6) concentrations have been considered to be a promising tumor marker for HCC. Down this line of research, high serum levels of interleukin-10 (IL-10) were found to be associated with poor HCC survival in patients undergoing surgical resection. Creactive protein (CRP) another inflammatory marker has also been identified as an important indicator predictive of survival in patients treated with surgical or non surgical therapies (Zhang et al., 2015).

Nitric oxide is another diagnostic marker for hepatocellular carcinoma and the estimation of nitric oxide has been reported to increase the sensitivity of detection and diagnosis of HCC (Abd El-Moety and Abd El-Moety, 2011). It has been found that $\mathrm{HCV}$ infection is associated with severe alterations in the host redox status where hepatic; blood and lymphocytic glutathione (GSH) contents were significantly depleted. Diminish in plasma antioxidant potentials and reduction in the levels of vitamins A, B, as well as zinc, and selenium were reported in HCV cases. In addition, significant increases in lipid peroxidation, DNA damage and nitrotyrosine have been also found (Madill et al., 2010). Moreover, Bansal and Simon (2018) reported that GSH level increased in human HCC as a result of increased expression of both glutamylcysteine synthetase heavy subunit (GCS-HS) and GS at the transcriptional level.

Chronic HCV infection differently modulates the apoptotic machinery where the virus induces apoptosis early in the course of infection, and as the disease progresses apoptosis is modulated (Zekri et al., 2011).In mammalian cells, apoptosis can be induced via two major pathways. One of them is the death receptor pathway (extrinsic pathway) which is considered an important 
Tarek Abdel Satter et al.

apoptotic system in cancer (Kumar, 2007).This pathway is triggered by binding Fas ligand (FasL) to Fas (CD95) with subsequent activation of caspase-8, which, in turn, activates the effector caspases 3, 6, and 7.

The development of reliable tumors marker that can detect HCC at earlier stages is essential. Predictive biomarkers are considered a key for the success of developing new drugs. The functions of tumor markers include prediction of prognosis therapeutic response as well as diagnosis or screening of cancer. The ideal biomarkers should be highly sensitive and specific for surveillance of high-risk populations and early detection of HCC and also be able to predict therapeutic outcome and provide a prognosis on survival.

The objective of the present study was to investigate the vascular adhesion molecule-1 (VCAM-1) and soluble platelet endothelial cell adhesion molecule 1(sPECAM-1) in patients with chronic hepatitis $\mathrm{C}$ and hepatocellular carcinoma. The reliability of these markers to predict early development of hepatitis $\mathrm{C}$ to hepatocellular carcinoma will be evaluated.

This study hypothesizes that the sVCAM-1 and sPECAM-1 may act as markers of $\mathrm{HCC}$ in $\mathrm{HCV}$ patients. Therefore, this work is designed in order to assess the correlation between SVCAM and sPECAM-1 and tumor features of patients with HCC.

Materials and Methods

\section{Study Population:}

One hundred and twenty patients enrolled in the National Hepatology and Tropical Medicine Research Institute (NHTMRI), during the period from September 2014 to March 2017,were divided into four groups as follows: The control group (Group I): this group included 20 normal healthy subjects whose ages ranged between 19 and 70 years and included 9 males and 11 females HCV group (Group II): this group included 50 patients with chronic hepatitis $\mathrm{C}$ genotype 4 and positive antibodies, but without HCC. Their ages ranged between 33 and 70 years and included 24 males and 26 females HCC group (Group III):this group included 25 patients with hepatocellular carcinoma (HCC) without HCV. There ages ranged between 45 and 70 years and included 13 males and 12 females $\mathrm{HCC}+\mathrm{HCV}$ group (Group IV): this group included 25 patients with proven chronic hepatitis $\mathrm{C}$ genotype 4 and developed hepatocellular carcinoma. Their ages ranged between 40 and 76 years and included 18 males and 7 females.

\section{Blood Sampling:}

Blood samples were collected from all cases, and the serum was separated for the biochemical determinations. Alpha fetoprotein (AFP) was measured using a commercial ELISA kit supplied by Abnova, as described by Chan and Miao (1986). The serum levels of reduced glutathione (GSH) and oxidized glutathione (GSSG) were analyzed according to the method described by $\mathrm{Hu}$ et al. (2003). To assess the serum total nitric oxide (NO) levels, an ELISA Kit manufactured by R\&D Systems, Inc., based on the method of Miles et al. (1996) was used. The levels of interleukin-6 (IL-6), interleukin8, and interleukin10 were determined using a commercially available kit manufactured by QuantiGlo ${ }^{\mathrm{R}}$ according to the method described by Naugler et al. (2008). Tumor necrosis factor alpha (TNFa), interferon gamma (IFN- $\gamma$ ), caspase-3 were measured according to the method described by Salek-Ardakani and Croft (2010); Billiau and Matthys (2009); Thornberry and Lazebnik respectively using commercial ELISA kits supplied by Abnova. Monocyte chemotactic Protein-1 (MCP-1) was estimated by a 
Evaluation of VCAM-1 and SPCAM-1 as biomarkers for the detection of Hepatocellular Carcinoma in patients with Hepatitis $\mathrm{C}$ virus

commercially available kit supplied by $R \& D$ Systems, Inc., based on the method describe by Sharma (2010). Soluble human platelet endothelial cell adhesion molecule-1 (sPECAM-1) and vascular cell adhesion molecule -1(VCAM-1) were measured according to the method described by Barreiro et al. (2002) and Govender et al. (1997) respectively. Finally, HCV-RNA was quantitated using Stratagene PCR Model MX 3000, viral RNA extraction kit supplied by QIAGen- Germany, and Brilliant QRT-PCR MasterMix, Stratagene, LaJolla, CA, USA.

Statistical Analyses:

The data obtained in the present work were represented in tables as mean values \pm standard error. Differences between groups were evaluated by one-way ANOVA. Once a significant $F$ value was obtained, LSD comparisons were performed to assess the significance of differences among various treatment groups. Three factorial analyses were performed to assess differences between ages versus sex and cases. Statistical analyses were carried out using the Statistical Package for the Social Science (SPSS) version 23USA. Sensitivity, specificity, positive and negative predictive values and diagnostic accuracy were calculated. The cut off values of the studied parameters for the patients' group was determined using receiver operating characterizing (ROC) curve analysis. Depending on HCV or $\mathrm{HCC}$ as positive groups, the data was expressed as an area under the curve (AUC). All reported pvalues were based on two-sided tests and compare to a significance level of $5 \%$ (Fischer et al. 2003).

\section{RESULTS}

Evaluation of AFP Marker and Oxidative Stress Indicators: (AFP, GSH, GSSG and TNO)

\section{Alpha fetoprotein (AFP):}

Statistical analysis of the data obtained from male and female patients revealed no significant differences in Alpha fetoprotein level in the HCV group as compared with the corresponding control value. However, there was a significant increase $(\mathrm{P}<0.001)$ in the HCC group and $\mathrm{HCV}+\mathrm{HCC}$ in both male and female patients in comparison with either the corresponding control or the $\mathrm{HCV}$ patients. Moreover, there was no significant difference between $\mathrm{HCV}+\mathrm{HCC}$ patients when compared with the HCC group. No gender differences were detected among the male and female patients in all the groups (Fig. 1).

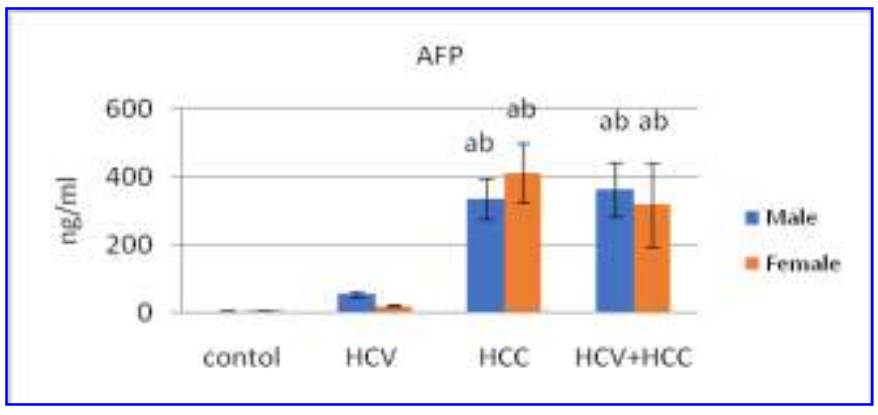

Fig. (1): Serum Alpha fetoprotein (AFP) in the four experimental groups (Control, HCV, $\mathrm{HCC}, \mathrm{HCV}+\mathrm{HCC})$.

Values are expressed as Mean $\pm \mathrm{SE}$ of ( $\mathrm{n}=9-25$ in each group). Level of significance at $\mathrm{p}<0.05$. a significant from corresponding control,b significant from corresponding HCV group, c significant from corresponding HCC group, and sindicates significant difference between male and female specimen within the same group. $\mathrm{HCV}=$ hepatitis $\mathrm{C}$ virus, $\mathrm{HCC}=$ hepatocellular carcinoma, and $\mathrm{HCV}+\mathrm{HCC}=$ hepatitis $\mathrm{C}$ virus plus hepatocellular carcinoma. 
Tarek Abdel Satter et al.

Reduced Glutathione (GSH) and increase in serum GSH contents in Oxidized Glutathione (GSSG):

Figure (2) shows that the serum GSH contents were significantly lower in all experimental groups than those of the corresponding control values in both male and female patients $(\mathrm{P}<0.001)$. The male HCC patients exhibited a significant comparison with the male HCV group $(p<0.001)$. No significant changes were recorded in the $\mathrm{HCV}+\mathrm{HCC}$ patients in comparison with both HCV or HCC groups, and no gender differences were recorded in the GSH contents among all the groups.

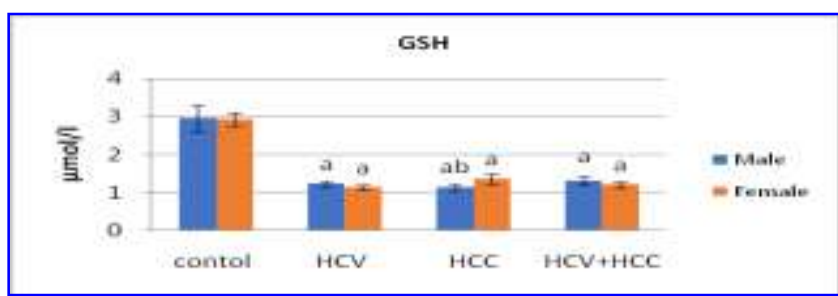

Fig. (2): Serum reduced glutathione (GSH) in the four experimental groups (Control, HCV, $\mathrm{HCC}, \mathrm{HCV}+\mathrm{HCC})$.

Values are expressed as Mean $\pm \mathrm{SE}$ of ( $\mathrm{n}=9-25$ in each group). Level of significance at $\mathrm{p}<0.05$. a significant from corresponding control,b significant from corresponding HCV group, c significant from corresponding HCC group, and sindicates significant difference between male and female specimen within the same group. $\mathrm{HCV}=$ hepatitis $\mathrm{C}$ virus, $\mathrm{HCC}=$ hepatocellular carcinoma, and $\mathrm{HCV}+\mathrm{HCC}=$ hepatitis $\mathrm{C}$ virus plus hepatocellular carcinoma.

There was no significant change in the GSSG in both male and female HCV patients in comparison with the corresponding control values. On the contrary, there was a highly significant increase in the HCC group in the GSSG contents as compared with the male and female corresponding control groups $(\mathrm{P}<0.001)$. No significant difference was detected in both male and female $\mathrm{HCV}+\mathrm{HCC}$ groups in the GSSG contents as compared with the corresponding control. The male and female HCC patients showed a significant increase in the GSSG contents when compared with the corresponding HCV group $(p<0.001)$. Meanwhile, GSSG contents were significantly decreased in the $\mathrm{HCV}+\mathrm{HCC}$ male patients in comparison with the male HCC patients $(\mathrm{p}<0.001)$. No significant change was found in the female group as compared with the corresponding HCC group (Fig. 3).

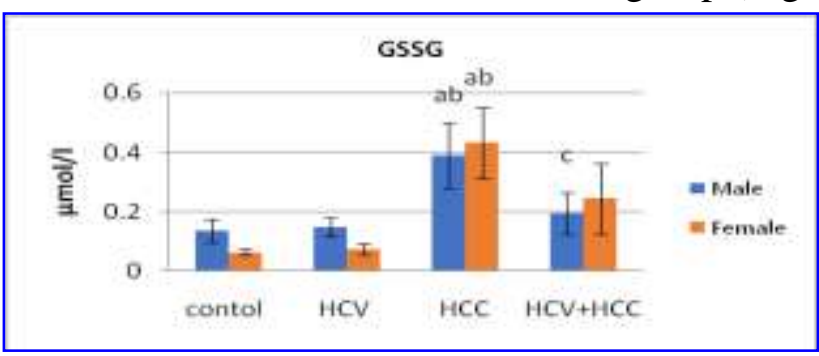

Fig. (3). Serum oxidized glutathione (GSSG) in the four experimental groups (Control, HCV, HCC, HCV+HCC).

Values are expressed as Mean $\pm \mathrm{SE}$ of ( $\mathrm{n}=9-25$ in each group). Level of significance at $\mathrm{p}<0.05$. a significant from corresponding control,b significant from corresponding HCV group, c significant from corresponding HCC group, and sindicates significant difference between male and female specimen within the same group. $\mathrm{HCV}=\mathrm{hepatitis} \mathrm{C}$ virus, $\mathrm{HCC}=$ hepatocellular carcinoma, and $\mathrm{HCV}+\mathrm{HCC}=$ hepatitis $\mathrm{C}$ virus plus hepatocellular carcinoma. 
Total nitric oxide (TNO):

Figure (4) shows a significant increase in the total nitric oxide (TNO) in the three experimental groups as compared with the corresponding controls $(\mathrm{p}<0.001)$ in both sexes. Moreover, analysis of data revealed a significant increase in the TNO in $\mathrm{HCC}$ and $\mathrm{HCV}+\mathrm{HCC}$ groups in both genders as compared with the corresponding HCV group $(p<0.001)$. The female
$\mathrm{HCV}+\mathrm{HCC}$ patients exhibited a significant decrease in serum TNO contents when compared with the corresponding HCC group. The statistical analysis revealed a significant decrease in the TNO only in the female $\mathrm{HCV}+\mathrm{HCC}$ patient as compared with the female HCC group. No gender differences were observed in the TNO among all the studied groups.

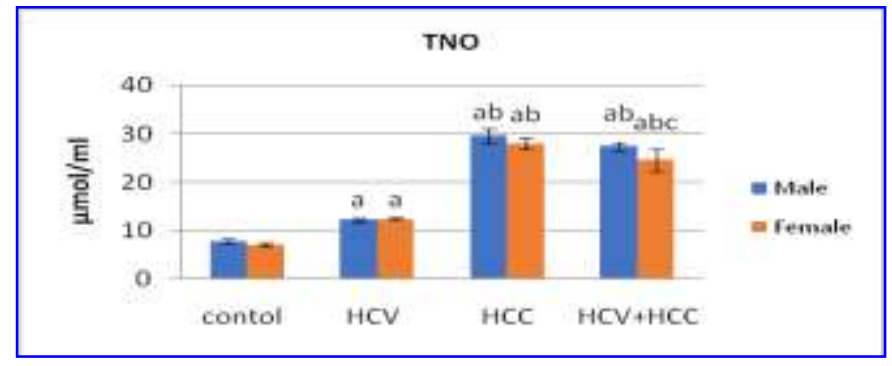

Fig. (4): Serum total nitric oxide (TNO) in the four experimental groups (Control, HCV, $\mathrm{HCC}, \mathrm{HCV}+\mathrm{HCC})$.

Values are expressed as Mean $\pm \mathrm{SE}$ of ( $\mathrm{n}=9-25$ in each group). Level of significance at $\mathrm{p}<0.05 .{ }^{a}$ significant from corresponding control, ${ }^{b}$ significant from corresponding HCV group, ${ }^{\mathrm{c}}$ significant from corresponding HCC group, and sindicates significant difference between male and female specimen within the same group. $\mathrm{HCV}=\mathrm{hepatitis} \mathrm{C}$ virus, $\mathrm{HCC}=$ hepatocellular carcinoma, and $\mathrm{HCV}+\mathrm{HCC}=$ hepatitis $\mathrm{C}$ virus plus hepatocellular carcinoma.

Proinflammatory Cytokines:

Interleukin-6 (IL-6) and Interleukin-10 (IL-10):

The values of serum IL- 6 and IL-10 were not significantly changed, although there was a consistent tendency to rise numerically in all experimental groups as compared with the corresponding control values as shown in Figures (5 \& 6).

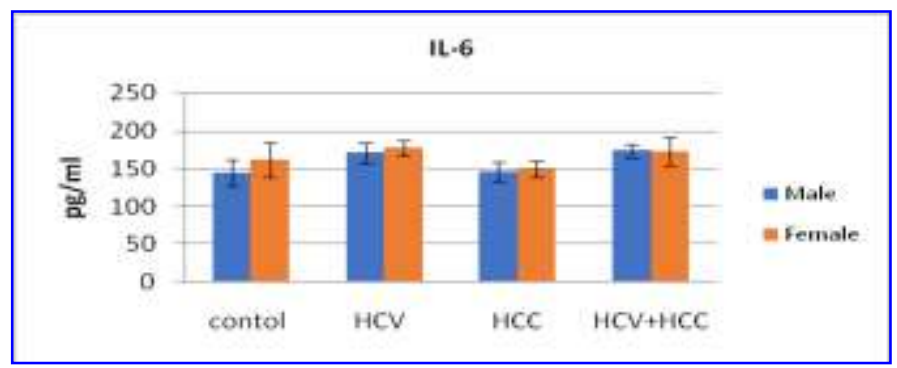

Fig. (5). Interleukin-6 (IL-6) in the four experimental groups (Control, HCV, HCC, $\mathrm{HCV}+\mathrm{HCC}$ ).

Values are expressed as Mean $\pm \mathrm{SE}$ of $(\mathrm{n}=9-25$ in each group). $\mathrm{HCV}=$ hepatitis $\mathrm{C}$ virus, $\mathrm{HCC}=$ hepatocellular carcinoma, and $\mathrm{HCV}+\mathrm{HCC}=$ hepatitis $\mathrm{C}$ virus plus hepatocellular carcinoma. 
Tarek Abdel Satter et al.

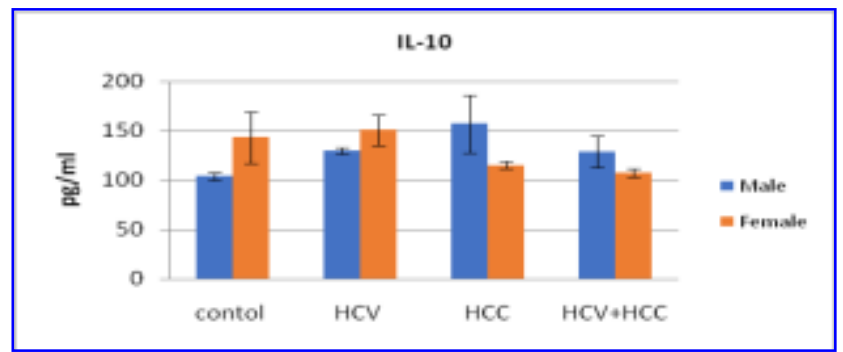

Fig. (6). Interleukin-10 (IL-10) in the four experimental groups (Control, HCV, HCC, $\mathrm{HCV}+\mathrm{HCC}$ ).

Values are expressed as Mean $\pm \mathrm{SE}$ of $(\mathrm{n}=9-25$ in each group). $\mathrm{HCV}=$ hepatitis $\mathrm{C}$ virus, HCC=hepatocellular carcinoma, and $\mathrm{HCV}+\mathrm{HCC}=$ hepatitis $\mathrm{C}$ virus plus hepatocellular carcinoma.

Interleukin-8 (IL-8):

The levels of this cytokines in the HCV male and female patients were not significantly different from the corresponding control values or from the other two experimental groups (Fig. 7). Nevertheless, the IL-8 values were significantly higher than those in the control and the HCV patients both in both sexes $(\mathrm{p}<0.001)$. Meanwhile, the HCC and
$\mathrm{HCV}+\mathrm{HCC}$ male and female patients exhibited a significant increase in the IL-8 levels in comparison with the either the corresponding control or the $\mathrm{HCV}$ groups ( $p<0.001)$, except in the male $\mathrm{HCV}+\mathrm{HCC}$ patients when compared with the corresponding HCV group, where there was no significant difference. No gender differences were recorded in serum IL-8 levels in all experimental groups.

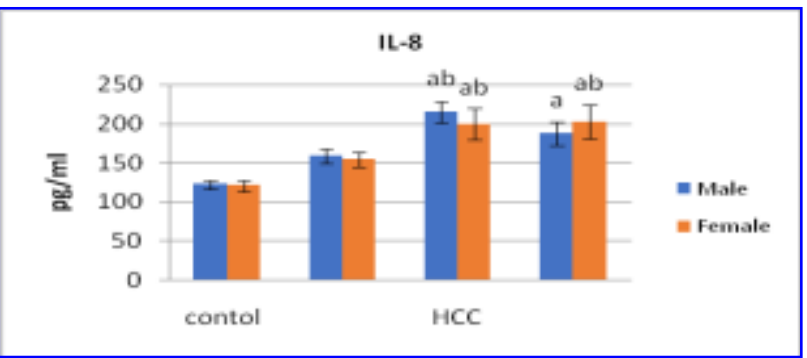

Fig. (7). Interleukin-8 (IL-8) in the four experimental groups (Control, HCV, HCC, HCV+HCC).

Values are expressed as Mean $\pm \mathrm{SE}$ of ( $\mathrm{n}=9-25$ in each group). Level of significance at $\mathrm{p}<0.05 .{ }^{a}$ significant from corresponding control, ${ }^{\mathrm{b}}$ significant from corresponding HCV group, ${ }^{\mathrm{c}}$ significant from corresponding HCC group, and sindicates significant difference between male and female specimen within the same group. $\mathrm{HCV}=\mathrm{hepatitis} \mathrm{C}$ virus, $\mathrm{HCC}=$ hepatocellular carcinoma, and $\mathrm{HCV}+\mathrm{HCC}=$ hepatitis $\mathrm{C}$ virus plus hepatocellular carcinoma.

Tumor Necrosis Factor- $\alpha$ (TNF- $\alpha)$ :

Figure (8) shows that tumor necrosis factor- $\alpha$ (TNF- $\alpha)$ in the HCV female patients was significantly increased $(p<0.001)$ as compared with the female control value. On the other hand, there was no significant change in the male patients when compared to the corresponding control values. In the male and female HCC patients, there was a significant increase in serum TNF- $\alpha$ when compared with the corresponding control or with the $\mathrm{HCV}$ groups. The male and female $\mathrm{HCV}+\mathrm{HCC}$ patients exhibited a significant increase as compared with the control group $(\mathrm{p}<0.001)$. Moreover, the male $\mathrm{HCV}+\mathrm{HCC}$ patients showed a significant decrease in the TNF- $\alpha$ levels when compared with the corresponding $\mathrm{HCC}$ values $(\mathrm{P}<0.001)$. 
Evaluation of VCAM-1 and SPCAM-1 as biomarkers for the detection of Hepatocellular Carcinoma in patients with Hepatitis $\mathrm{C}$ virus

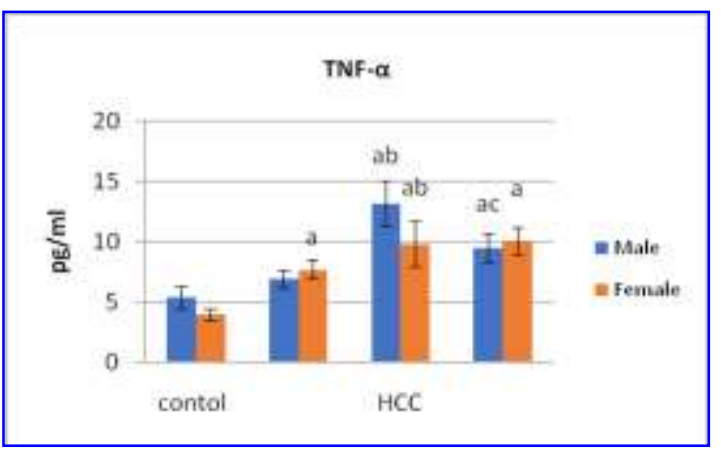

Fig. (8). Tumor necrosis factor- $\alpha$ (TNF- $\alpha)$ in the four experimental groups (Control, HCV, $\mathrm{HCC}, \mathrm{HCV}+\mathrm{HCC})$.

Values are expressed as Mean $\pm \mathrm{SE}$ of ( $\mathrm{n}=9-25$ in each group). Level of significance at $\mathrm{p}<0.05 .{ }^{a}$ significant from corresponding control, ${ }^{b}$ significant from corresponding HCV group, ${ }^{c}$ significant from corresponding HCC group, and sindicates significant difference between male and female specimen within the same group. $\mathrm{HCV}=$ hepatitis $\mathrm{C}$ virus, $\mathrm{HCC}=$ hepatocellular carcinoma, and $\mathrm{HCV}+\mathrm{HCC}=$ hepatitis $\mathrm{C}$ virus plus hepatocellular carcinoma.

Interferon- $\gamma($ INF- $\gamma)$ :

The values of serum INF-rwere not statistically different among all the groups or between sexes within each group (Fg. 9).

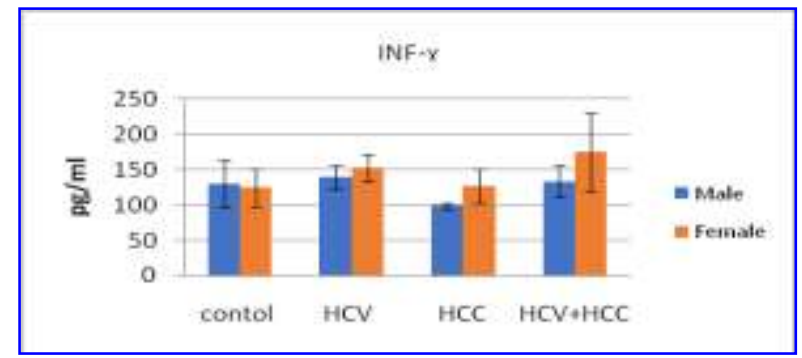

Fig. (9). Interferon-r (INF-r)in the four experimental groups (Control, HCV, HCC, HCV+HCC).

Values are expressed as Mean $\pm \mathrm{SE}$ of ( $\mathrm{n}=9-25$ in each group). Level of significance at $\mathrm{p}<0.05, \mathrm{HCV}=$ hepatitis $\mathrm{C}$ virus, $\mathrm{HCC}=$ hepatocellular carcinoma, and $\mathrm{HCV}+\mathrm{HCC}=$ hepatitis $\mathrm{C}$ virus plus hepatocellular carcinoma.

Soluble platelets endothelial cell adhesion molecule-1(sPECAM-1) and vascular cell adhesion molecule-1(VCAM-1):

The values of serum sPECAM-1 and VCAM-1 were numerically, but not significantly increased in all the experimental groups as compared with the corresponding control values as shown in Figures $(10$ \& 11), exceptin female $\mathrm{HCV}+\mathrm{HCC}$ patients where there was a significant decrease in the VCAM-1 in comparison with the corresponding $\mathrm{HCV}$ group. 
Tarek Abdel Satter et al.

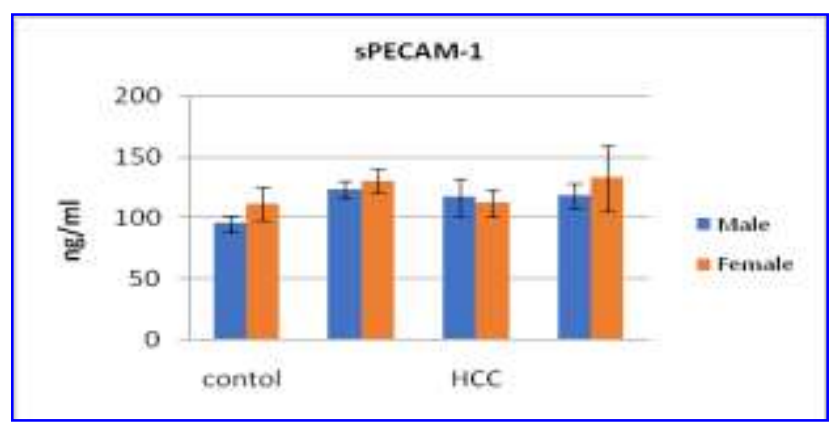

Fig. (10). Soluble platelets endothelial cell adhesion molecule-1 (sPECAM-1) in the four experimental groups (Control, $\mathrm{HCV}, \mathrm{HCC}, \mathrm{HCV}+\mathrm{HCC}$ ).

Values are expressed as Mean $\pm \mathrm{SE}$ of ( $\mathrm{n}=9-25$ in each group). Level of significance at $\mathrm{p}<0.05$. HCC=hepatocellular carcinoma

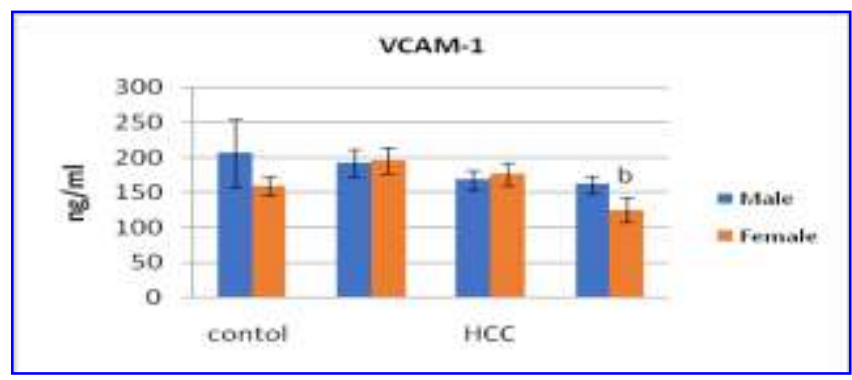

Fig. (11): Vascular cell adhesion molecule-1(VCAM-1) in the four experimental groups (Control, HCV, HCC, HCV+HCC).

Values are expressed as Mean $\pm \mathrm{SE}$ of ( $\mathrm{n}=9-25$ in each group). Level of significance at $\mathrm{p}<0.05 .{ }^{\mathrm{b}}$ significant from corresponding $\mathrm{HCV}$ group, , $\mathrm{HCC}=$ hepatocellular carcinoma

\section{Caspase-3 (casp-3):}

Serum caspase-3 was not significantly changed in the HCV male and female patients when compared with the corresponding control values. Moreover, both male and female $\mathrm{HCC}$ and $\mathrm{HCV}+\mathrm{HCC}$ patients exhibited a tendency of decreased caspase-3 when compared with the control values, but this decrease was not statistically significant (Fig. 12).

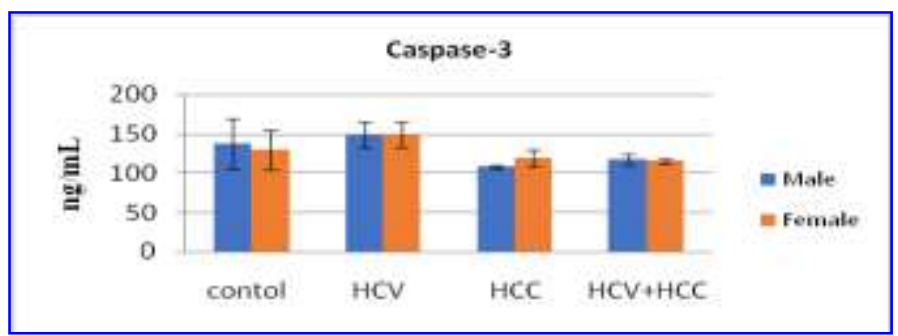

Fig. (12): Serum Caspase-3 in the four experimental groups (Control, HCV, HCC, $\mathrm{HCV}+\mathrm{HCC}$ ).

Values are expressed as Mean $\pm \mathrm{SE}$ of ( $\mathrm{n}=9-25$ in each group). Level of significance at $\mathrm{p}<0.05$. $\mathrm{HCV}=\mathrm{hepatitis} \mathrm{C}$ virus, $\mathrm{HCC}=$ hepatocellular carcinoma, and $\mathrm{HCV}+\mathrm{HCC}=$ hepatitis $\mathrm{C}$ virus plus hepatocellular carcinoma. 
Evaluation of VCAM-1 and SPCAM-1 as biomarkers for the detection of Hepatocellular Carcinoma in patients with Hepatitis $\mathrm{C}$ virus

Monocyte Chemotactic Protein-1 (MCP1):

There was no significant increase in the MCP-1 in male and female HCV patients when compared with the corresponding control. However, there was a slightly significant increase in the male and female $\mathrm{HCC}$ and $\mathrm{HCV}+\mathrm{HCC}$ groups in comparison with the corresponding control values $(\mathrm{p}<0.001)$. The HCC patient of both sexes exhibited MCP-1 levels higher than those of the corresponding HCV patients $(\mathrm{P}<0.05)$. The MCP-1 levels in the $\mathrm{HCV}+\mathrm{HCC}$ male and female patients were significantly higher $(\mathrm{P}<0.05)$ than the control values, but were not significantly different from the corresponding values recorded in the HCV or HCC patients (Fig. $13)$.

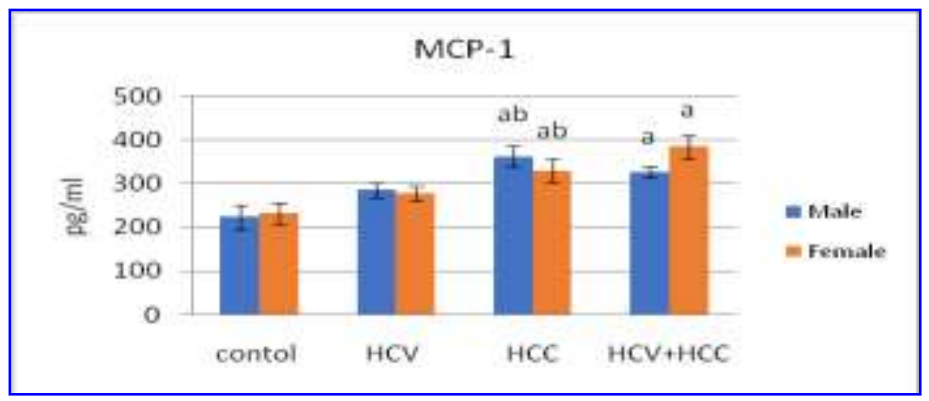

Fig. (13). Serum Monocyte Chemotactic Protein-1 (MCP-1) in the four experimental groups (Control, HCV, HCC, HCV+HCC).

Values are expressed as Mean $\pm \mathrm{SE}$ of ( $\mathrm{n}=9-25$ in each group). Level of significance at $\mathrm{p}<0.05$.

a significant from corresponding control, ${ }^{\mathrm{b}}$ significant from corresponding HCV group,

$\mathrm{HCV}=$ hepatitis $\mathrm{C}$ virus, $\mathrm{HCC}=$ hepatocellular carcinoma, and $\mathrm{HCV}+\mathrm{HCC}=$ hepatitis $\mathrm{C}$ virus plus hepatocellular carcinoma.

Analysis of Receiver Operating Characterizing (ROC) Curve 1-ROC curve dependent on hepatitis $C$ virus PCR results as a positive group: A-sPECAM-1 and VCAM-1:

Figure (14) shows that, sPECAM-1 was a poor discriminant power with high significance at $\mathrm{p}=0.003$ with $\mathrm{AUC}=0.664$ and cut-off $102.5 \mathrm{ng} / \mathrm{ml}$ and $68 \%$ sensitivity and $68.9 \%$ specificity. In this regard, CAM1 was not a discriminant power and was not significant with $\mathrm{AUC}=0.521$ ) at cut-off $244.5 \mathrm{ng} / \mathrm{ml}$ and $13.3 \%$ sensitivity and $97.8 \%$, specificity.

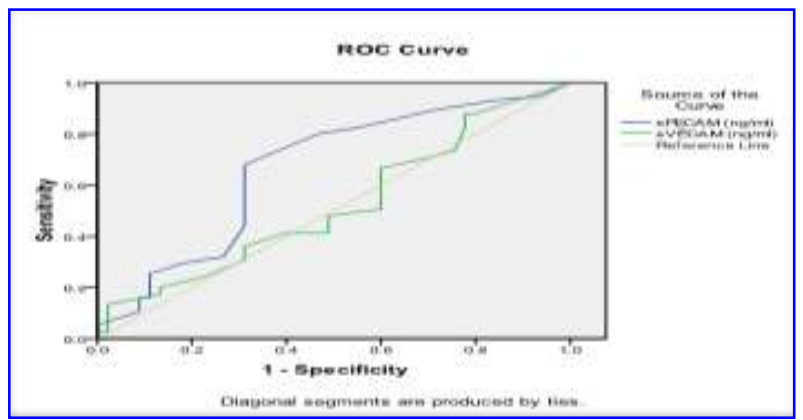

Fig. (14). Analysis of ROC curve showing the sensitivity and specificity of SPECAM-1 and SVCAM-1 dependent on positive PCR. 
Tarek Abdel Satter et al.

B- Caspase-3, AFP and MCP-1:

The results presented in figure (15) show that caspase-3 was highly significant at $\mathrm{p}=0.000$ with fair discriminant power at $\mathrm{AUC}=0.744$ and a cut-off at $112.5 \mathrm{ng} / \mathrm{ml}$ and highly sensitive (72\%) and specific
(73.3\%). On the other hand, AFP and MCP1 were not discriminant power at $\mathrm{AUC}=$ 0.560 ) and no significance was noticed with cut-off at $5.05 \mathrm{ng} / \mathrm{ml}$ and $232 \mathrm{pg} / \mathrm{ml}$ with sensitivity $(94.7 \%$ and $81.3 \%)$ and specificity $(31.3 \%$ and $32.6 \%$ ) respectively

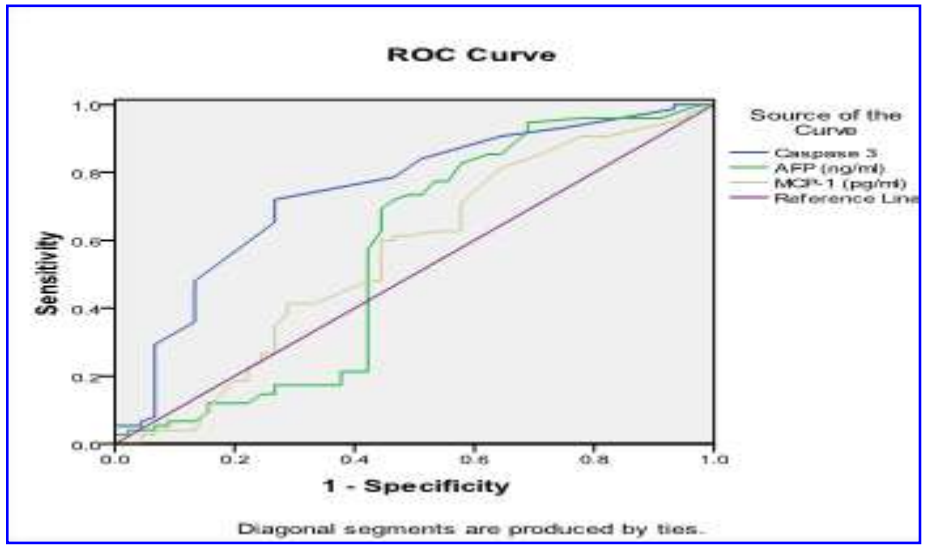

Fig. (15): Analysis of ROC curve showing sensitivity and specificity of caspase-3, AFP and MCP-1 dependent on positive PCR.

\section{C-IL-6, IL-10 and IL-8:}

There was a poor discriminant power and significance in serum IL-6 at $\mathrm{p}=0.007$ with $\mathrm{AUC}=0.647$ and $78.7 \%$ sensitivity and $51.1 \%$ specificity with $125 \mathrm{pg} / \mathrm{ml}$ cutoff. Moreover, IL-10 had a poor discriminant power and low significant change at $\mathrm{p}=0.011$ with $\mathrm{AUC}=0.639$ at 131 $\mathrm{pg} / \mathrm{ml}$ cut-off, but low sensitivity $(38.7 \%)$ and specificity $86.7 \%$ ). Meanwhile, serum IL-8 showed no significant change and no discriminant power at $\mathrm{AUC}=0.526$ and $130.5 \mathrm{pg} / \mathrm{ml}$ cut-off with sensitivity $77.3 \%$ and specificity $40 \%$

(Fig.16).

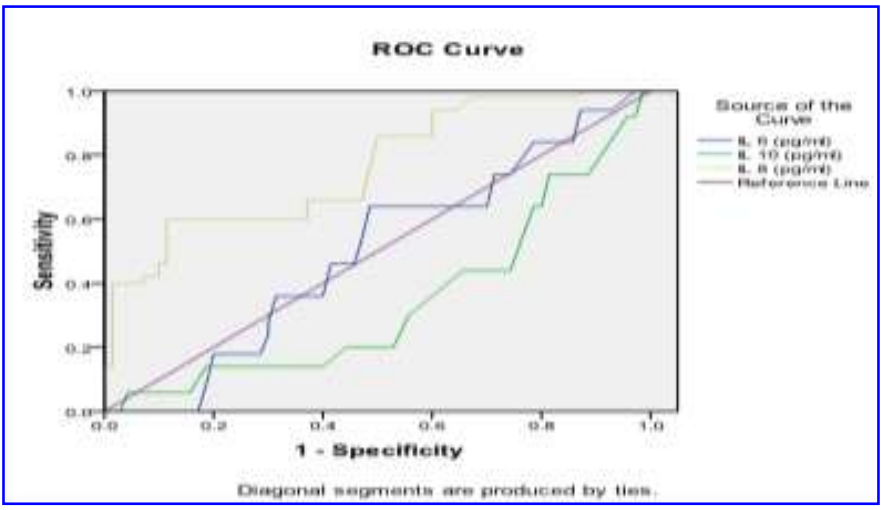

Fig. (16): Analysis of ROC curve sensitivity and specificity of IL-6, IL-10 and IL-8 dependent on positive PCR. 
Evaluation of VCAM-1 and SPCAM-1 as biomarkers for the detection of Hepatocellular Carcinoma in patients with Hepatitis $\mathrm{C}$ virus

\section{D- TNF- $\alpha$ and INF- $\gamma$ :}

TNF- $\alpha$ was not a discriminant power and not significant at $\mathrm{p}=0.551$ with $\mathrm{AUC}=$ 0.533 at cut-off $4.85 \mathrm{pg} / \mathrm{ml}$, sensitivity $82.5 \%$, and specificity $33.1 \%$. On the contrary, analysis of ROC curve revealed a significant change in INF- $\gamma$ at $p=0.000$ and fair discriminant power at $\mathrm{AUC}=0.702$ with $65.3 \%$ sensitivity and $82.2 \%$ specificity at cut-off $=102.5 \mathrm{pg} / \mathrm{ml}$, as shown in figure (17).

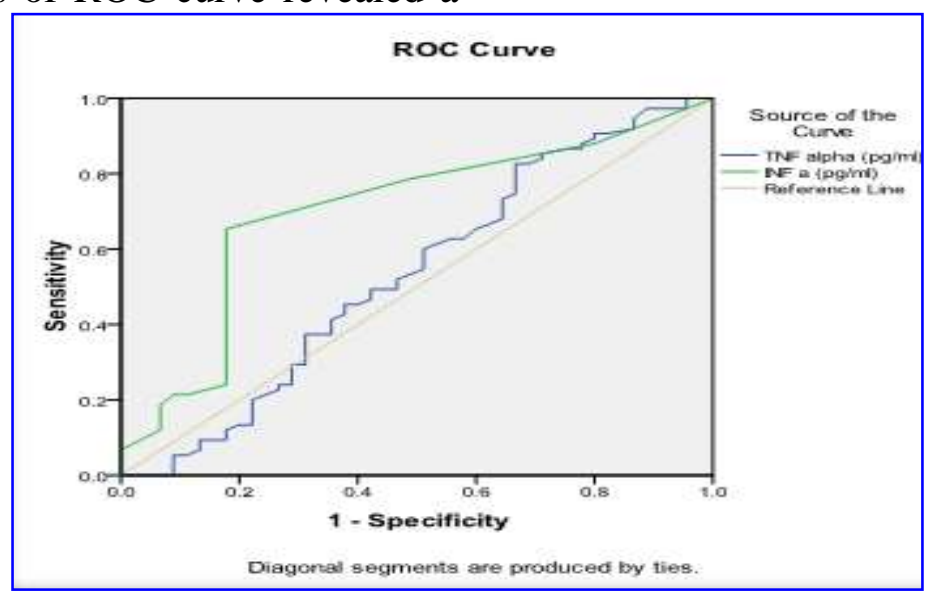

Fig. (17): Analysis of ROC curve showing sensitivity and specificity of TNF- $\alpha$ and INF- $\gamma$ dependent on positive PCR.

1-ROC curve for detection of HCC: A-sPECAM-1 and VCAM-1:

sPECAM-1 concentration specificity and sensitivity for detection of $\mathrm{HCC}$ is shown in Figure (18), ROC curve analysis showed no discriminateF power
(AUC=0.427), sensitivity $14 \% \quad$ and specificity $92.5 \%$ at cut-off $195 \mathrm{ng} / \mathrm{ml}$. On the other hand, sVCAM-1 was not significantly changed at $\mathrm{p}=0.084$ with no discriminate power at $\mathrm{AUC}=0.521$ and $1 \%$ sensitivity and

$0 \%$ specificity

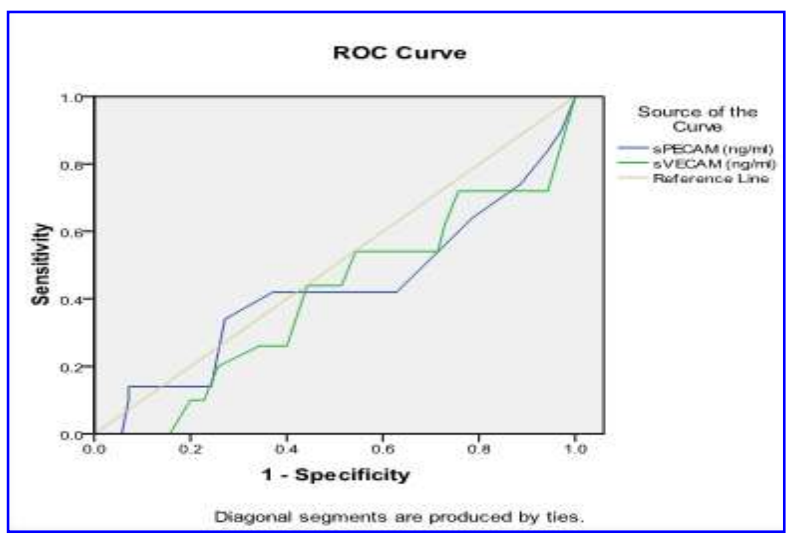

Fig. (18). Analysis of ROC curve showing sensitivity and specificity of sPECAM-1 and SVCAM-1 for detection of HCC. 
Tarek Abdel Satter et al.

Caspase-3, AFP and MCP-1:

As shown in figure (19), caspase-3 was not a discriminate power $(\mathrm{AUC}=0.303$ ) at cut-off $97.5 \mathrm{ng} / \mathrm{ml}$ (sensitivity 100 and specificity $5.7 \%$ ). On the other hand, ROC curve analysis showed fair a discriminate power for serum AFP and MCP-1 concentration for detection of $\mathrm{HCC}$ with AUC (0.777 and 0.773) respectively. The best cut-off levels were identified as $163.5 \mathrm{ng} / \mathrm{ml}$ and $265 \mathrm{pg} / \mathrm{ml}$, respectively with sensitivity of $70 \%$ and $96 \%$ and specificity of $100 \%$ and $64.3 \%$

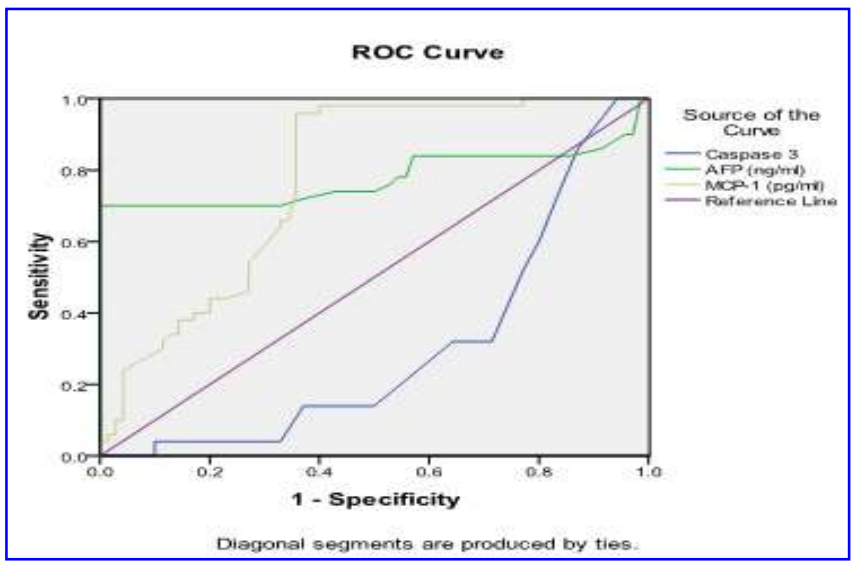

Fig. (19). Analysis of ROC curve showing the sensitivity and specificity of caspase-3, AFP, and MCP-1 for detection of HCC.

\section{IL-6, IL-10 and IL-8:}

The values of serum IL-6 and IL-10 were not significant in the ROC curve analysis with the AUC values 0.496 and 0.342 respectively and no discriminant power for detection of $\mathrm{HCC}$ at cut-off levels of $144.5 \mathrm{pg} / \mathrm{ml}$ and $279 \mathrm{pg} / \mathrm{ml}$ respectively and sensitivity $64 \%$ and $6 \%$ along with specificity of $51.4 \%$ and $95.7 \%$ respectively (Fig. 20). IL-8 ROC curve showed significant change and good discriminate power for detection of $\mathrm{HCC}$ with $\mathrm{AUC}=$ 0.764 at cut-off $189.5 \mathrm{pg} / \mathrm{ml}$ and sensitivity $60 \%$ and $88.6 \%$.

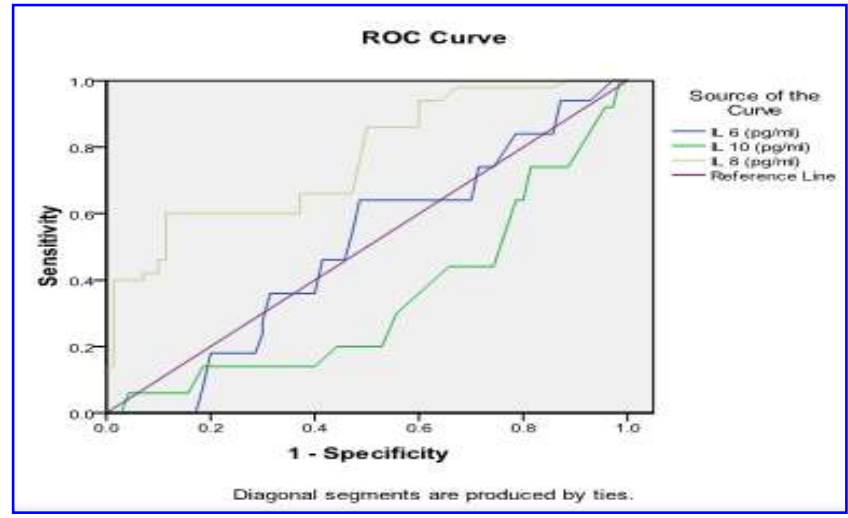

Fig. (20): Analysis of ROC curve showing sensitivity and specificity of IL-6, IL-10 and IL-8 for detection of $\mathrm{HCC}$. 
TNF- $\alpha$ and INF- $\gamma$ :

A significant change was noticed in the TNF- $\alpha$ at $p=0.000$ and fair discriminant power $\quad(\mathrm{AUC}=0.731)$, sensitivity $86 \%$, specificity $50 \%$ at cut-off $5.75 \mathrm{pg} / \mathrm{ml}$. On the contrary, INF- $\gamma$ was not significant in the ROC curve with $\mathrm{AUC}=0.298$ at cut-off $130.5 \mathrm{pg} / \mathrm{ml}$ with no discriminant power at sensitivity $22 \%$ and specificity $78.6 \%$ (Fig. 21).

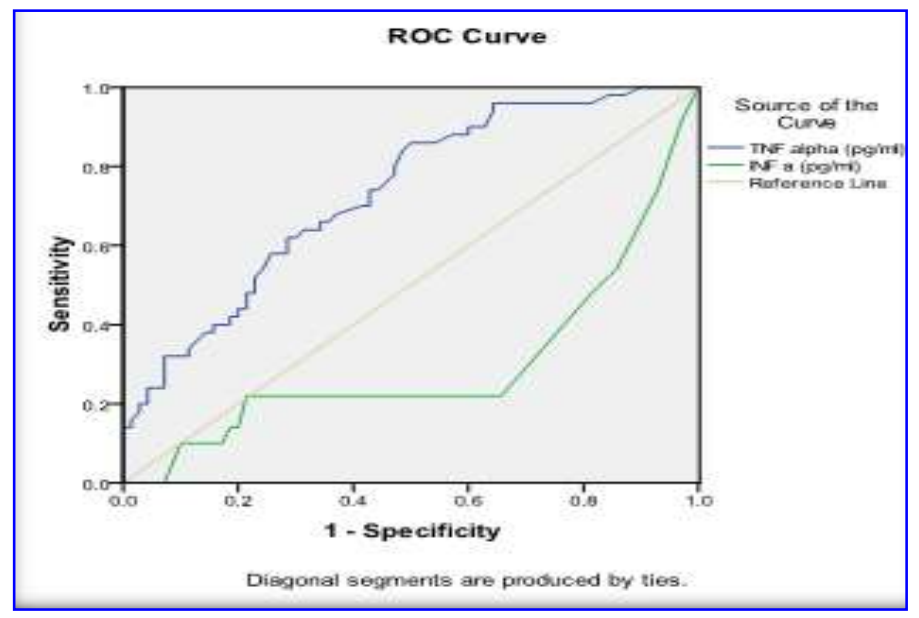

Fig. (21). Analysis of ROC curve showing sensitivity and specificity of TNF- $\alpha$ and INF- $\gamma$ for detection of $\mathrm{HCC}$.

\section{DISCUSSION}

Hepatitis $\mathrm{C}$ virus is a leading etiology of hepatocellular carcinoma. In most cases, the virus causes $\mathrm{HCC}$ in the presence of chronic hepatic inflammation, advanced fibrosis and cirrhosis. The interaction of $\mathrm{HCV}$ with its human host is complex and multidimensional. The direct and indirect mechanisms of $\mathrm{HCV}$-induced HCC include activations of multi-host pathways such as liver fibrogenic pathways, cellular and survival pathways, interaction with immune and metabolic systems (Dandachi et al., 2018). In the last years, studies have focused on the factors that affect or modify the likelihood of HCC development in patients with hepatitis $\mathrm{C}$ (Abbas and Abbas, 2018).

The accumulated data from studies on the mechanisms of cellular oxidative stress showed that it activates signaling cascades, which can seriously influence the regulation of cell growth and transformation processes. It has been reported that oxidative stress plays a key role in HCC development and progression (Takaki et al., 2015). Glutathione is the most abundant biological antioxidant produced in the liver and a decreased level of GSH is associated with enhanced oxidative stress and increased production of GSSG (Bansal and Simon, 2018). In the present study, there was a significant decrease in GSH concomitant with an increase of GSSG in the HCC group as compared with the control or the HCV patients. Accumulating evidence established that oxidative stress plays an important role in the development of liver carcinogenesis through disrupting either normal cell function or the genetic materials and interfering with the pathways of signal transduction. Therefore, elucidation of the impact of oxidative stress on the development of liver carcinogenesis is very important for the prevention and treatment of HCC (Takaki et al., 2015; Wang et al., 
Tarek Abdel Satter et al.

2016). In addition, oxidative stress is triggered by inflammatory signals and affects multiple cells in the liver, such as the sinusoidal endothelial cells (LSECs), hepatic stellate cells (HSCs), dendritic cells (DCs), and Kupffer cells (KCs). These cells produce many kinds of immune mediators, cytokines, and chemokines. For example, IL- 6 is an important proinflammatory cytokine that can inhibit cellular apoptosis. Tumor necrosis factor alpha $(\mathrm{TNF}-\alpha)$ is a proinflammatory immune mediator that induces tissue damage, promotes the production ofother cytokines, replenishes inflammatory cells, promotes the occurrence of fibrosis, and further activates the OS reaction. One of the important functions of TNF- $\alpha$ is to activate cellular apoptotic and/or antiapoptotic pathways (Wang et al., 2016).

Nitric oxide (NO) is a soluble gas synthesized by the vascular endothelium with several functions essential for the vascular homeostasis. These functions include protection of the vessels from injuries caused by cells and platelets circulating in the blood, maintaining the vascular dilator tone, and regulation of endothelial cell growth (Tousoulis et al., 2012). One of the most important reactive oxygen species derived by molecular oxygen is the nitric oxide radicals. The elevation of total nitric oxide (TNO) in the present study is in agreement with $\mathrm{Abd} \mathrm{El}$ Moety andAbd El Moety (2011). They reported that NO acts as a pro-apoptotic inducer in some cell types or as an antiapoptotic modulator in other cell types, including hepatocytes. Nitric oxide is reactively induced by the hepatic tissue surrounding $\mathrm{HCC}$ by three independent mechanisms; firstly, tumor cells stimulate macrophages and Kupffer cells to produce NO; secondly, HCC produces a variety of cytokines that may stimulate hepatocytes to produce NO; and finally, a marked disturbance of liver function in HCC patients may be associated with increased portosystemic shunting and further development of hyperdynamic circulation, leading to an increase in NO production (Eissa et al., 2013). Moreover, NO binds and activates guanylate cyclase, which, in turn, catalyzes the conversion of GTP to the second messenger molecule cyclic GMP. High concentrations of NO protect tumor cells from apoptosis, promote vasodilation, and enhance the angiogenic effects (Marra et al., 2011).

Angiogenesis and inflammation are two host-dependent and interdependent hallmarks of cancer (Grivennikov et al., 2010) that have an early permissive role in tumorigenesis. Inflammation plays an important role in the pathogenesis and progression of malignant tumors including HCC because of promoting tumor angiogenesis, invasion, and metastasis through a subset of regulatory chemokines (Capece et al., 2013). IL-6 is one of the major immune-regulatory cytokines which seems to play a major role in inflammation. Moreover, IL-6 is involved in the autocrine growth of many cancer cells by increasing their capacity to secrete matrix metalloproteinase-9 (Marquardt and Edlich, 2019).

Based on the results drawn from this work, serum levels of IL-6, IL-10 and INF- $\gamma$ were not significantly altered in all the investigated groups. These results may be explained by one or more of the following reasons; firstly, the inflammatory response is beneficial to the host, however, when tissue homeostasis is chronically perturbed, interactions between innate and adaptive immune cells can be disturbed. It seems that altered interactions between the immune cells of these two types of immunity may lead to chronic inflammatory disorders. Secondly, the failure to appropriately engage and/or disengage the immune system can 


\section{Evaluation of VCAM-1 and SPCAM-1 as biomarkers for the detection of Hepatocellular Carcinoma in patients with Hepatitis $\mathrm{C}$ virus}

lead to excessive tissue remodeling. Thirdly, possible loss of tissue architecture from excessive cell growth. Finally, the impact of oxidative stress-related protein and DNA alterations as well as stimulation of processes causing apoptosis or necrosis. Under some circumstances, these effects can lead to an increased risk of cancer development (Balkwill and Mantovani, 2001). In addition to the previously mentioned points, the progressive damage in liver tissue prevents wound healing due to the variety of cytokines receptors present in hepatocytes (Vikram et al., 2011). The excessive cytokines fall in surrounding tissues resulting in a decrease in cytokines level in HCC tumor versus healthy individuals (Zekri et al., 2005). Besides, Caiet al. (2019) reported that some potential bias in relatively small samples showed that cytokines are not used as a new predicator until large prospective studies. If the study only included patients as randomized selected samples, the cytokines then may not represent reliable markers. Furthermore, patients could be receiving antiviral treatments that reduce hepatic necroinflammatory response and liver injury (Liaw et al., 2004). Moreover, IL-6 takes a relatively long time to increase (Wong et al., 2009), therefore it will lag behind other inflammatory responses that should all work coherently as a complex network (Liu et al., 2018) or in a sequential cascade fashion (Jung and Miller, 2008).

It is relevant to mention that Wong et al. (2009) attributed these cytokine decreases after surgical resection of HCC to some inflammatory responses affected by the cytokine's environment. To add to the tangents of the situation, metastatic patients were reported to exhibit low levels of these cytokines (Budhu and Wang, 2006). Moreover, INF- $\gamma$ activates macrophages and increases TNF- $\alpha$ mediated liver damage, while TNF- $\alpha$ is not activated by macrophages if there are low levels of INF- $\gamma$ (Budhu and Wang, 2006). Dudakov et al. (2015) suggested that IL-6 does not actually serve pro- or anti- inflammatory functions; instead, it seems to act as a regenerative or metastatic molecule. Along with this line of reasoning, IL-6 was found to correlate with tumor size and number, as well as with metastasis, and consequently represents an unfavorable prognostic indicator in $\mathrm{HCC}$ (Jekarl et al., 2019).

Studies by Porta et al. (2008) and Bai et al. (2017) support the conception that IL-10 is associated with the progression of $\mathrm{HCV}$. Consequently, it is reasonable to correlate the increases in IL-10 with the chronic liver disease. In addition, Vikram et al. (2011) suggested that the balanced and fine tuning between IL-10 and TNF- $\alpha$ is crucial for prevention of HCC development and that low levels lead to progressive damage to liver tissue and prevent wound healing. Also, Budhu and Wang (2006) and Wong et al. (2009) observed that IFN- $\gamma$ may not play a prominent role in liver inflammation and progressive liver damage.

Concurrently, in the present study, IL-8 was slightly increased in HCC and $\mathrm{HCV}+\mathrm{HCC}$ group as compared to the control or HCV groups. This increase may be explained by IL-8-induced proliferation of various HCC cell lines (Budhu and Wang, 2006) and/or by the production of immunosuppressive cytokines such as IL10 , transforming growth factor- $\beta$ (TGF $\beta$ ), and certain chemokines (Burkholder et al, 2014). Moreover, Budhu and Wang (2006) reported a unique innate immunity signature within the tumor microenvironment that promotes HCC metastasis which includes an increase in immunosuppressive cytokines (IL-4, IL-5, IL-8, and IL-10) accompanied by suppression of immune-activating cytokines IL-1, TNF- $\alpha$, and IFN- $\gamma$. 
Tarek Abdel Satter et al.

As the present work revealed, the TNF- $\alpha$ level was significantly increased in the HCC group as compared with the control or HCV groups. While only HCV female group exhibited a significant increase as compared with the control group. These results align with those of the National Comprehensive Cancer Network (2017) and Ghafar et al. (2019) in showing that continued cytokine-induced hepatocyte damage followed by hepatocyte regeneration leads to HCC development. The role of cytokines such as IL-1, IL-2, IL-6, IL-10, IL-12, and TNF- $\alpha$ in hepatocarcinogenesis and TNF- $\alpha$, produced by endothelial cells and inflammatory cells, is thought to be induced via the nuclear factor kappa B (NF$\kappa \mathrm{B})$ activation in hepatocytes (Baltimore, 2009). However, (Pikarsky et al. (2004) suggested that this process is required for progression to $\mathrm{HCC}$, but not for hepatocyte transformation. The current results are also in agreement with those of Karimi et al. (2009) and Baghel et al. (2014) who reported that high serum IL-6 level predates the development of HCC in chronic hepatitis $B$ patients and has moderate accuracy in predicting future types of cancer.

Nakagawa et al. (2012) and Marquardt and Edlich (2019) demonstrated that TNF- $\alpha$ plays a dual role in cancer etiology. As a tumor suppressor, TNF- $\alpha$ remodels the tumor microenvironment by increasing activity of cytotoxic $\mathrm{T}$ cells, promoting maturation of dendritic cells, and inhibiting tumor angiogenesis. TNF- $\alpha$ also signals directly to cancer cells to promote apoptosis and alter expression of MHC proteins, promoting recognition to $\mathrm{T}$ cells. As a tumor promoter, TNF- $\alpha$ increases EMT of cancer cells and increases activity of Tregs (Yao et al., 2016; Alqahtani, 2019)

In this regard, Fallahi et al. (2012) suggested that cytokines act as intercellular mediators involved in viral control and liver damage induced by $\mathrm{HCV}$ infection. The complexity of the cytokines network operating in an intricate manner during initial infection allows a coordinated and effectivedevelopment ofboth innate and adaptive immune responses. However, a cluster of differentiation $8(\mathrm{CD} 8+)$ cytotoxic $\mathrm{T}$ lymphocytes (CTLs) may work to clear viruses using apoptosis-related cytolytic mechanisms and mechanisms mediated by type 1 cytokines (IFN- $\gamma$, TNF- $\alpha$ ) secreted by NK and NKT. Nevertheless, when the specific immune response fails to control viral replication, the infected liver cells secrete IFN- $\gamma$-induced chemokines, which results in the migration of nonspecific mononuclear cells into the liver (Larrubia et al., 2008).

The present results revealed that there was no significant change in serum VCAM-1 in HCV, HCC and $\mathrm{HCV}+\mathrm{HCC}$ patients as compared with the control subjects. The exact mechanism of differences between individuals with decreases or increases of serum VCAM-1 in HCC is unclear. The source of VCAM-1 in the circulation of HCC patients could come from activated endothelial cells in both the tumor and chronic hepatitis or cirrhosis in the non- tumorous liver. The serum VCAM1 levels may reflect the activity of these cells and may be also originating from activated dendritic cells localized in the portal tracts (Bruno et al., 2005). Previous studies ofBruno et al. (2005); Kukla et al. (2009) and Diaz-Sanchez et al. (2013) reported that sVCAM-1 is more closely associated with the presence of HCC. The normal liver contains an enormous number of lymphocytes such as specialized natural killer (NK), natural killer $\mathrm{T}$ lymphocyte (NKT), CD4+ and CD8+ cells (Kukla et al., 2009). Moreover, CD8 lymphocytes infiltrating the liver during chronic hepatitis C, express VLA-4 on its cell membrane, confirming the participation of this molecule in cellular adhesion. Binding $\mathrm{T}$ cells by 


\section{Evaluation of VCAM-1 and SPCAM-1 as biomarkers for the detection of Hepatocellular Carcinoma in patients with Hepatitis $\mathrm{C}$ virus}

VLA-4/VCAM-1 complex may cause T-cell activation and proliferation leading, in consequence, to damage of the surrounding hepatocytes (De Castro et al., 2010). HCV infection leads to inflammatory processes of different grades that involve activation of adhesion molecules and cytokines which facilitate the recruitment of leukocytes to the inflamed areas, which in turn, increase the number of lymphocytes in the liver. The extravasation of leukocytes into the inflammatory tissue is a phenomenon that involves several sequential steps and requires a wide spectrum of adhesion molecules (Ragab and Hussein, 2016). This migration requires molecular interaction involved in firm adhesion of leukocytes interfered by function antigen-1/intercellular adhesion molecule-1 (LFA-1/ICAM-1) and very late antigen-4/vascular cell adhesion molecule-1 (VLA-4/VCAM-1)complexes as well as receptors located at the endothelial cells (EC) junctions, such as platelet endothelial cell adhesion molecule-1 (PECAM-1) (Hintermann and Christen, 2019). Nonetheless, VCAM-1 (CD 106) expression on $\mathrm{EC}$ is not constitutive, but can be induced by TNF- $\alpha$, IL-1, IL-4 and INF- $\gamma$ and IFN- $\gamma$. There is usually a low basal expression of VCAM-1 in the normal liver tissue, both on the sinusoidal and Kupfer cells, as well as the membrane-bound forms. Soluble forms sVCAM-1 and sPECAM-1 also exist in human plasma (Kukla et al., 2009). In agreement with the aforementioned layout, the present study revealed that serum levels of TNF- $\alpha$ and IFN- $\gamma 1$, and VCAM- 1 were not significantly changed.

There were slight, but not significant, increases in the soluble human platelets endothelial cell adhesion molecules (sPECAM) levels in the HCV and HCC patients, as compared with the control values. This tendency of sPECAM to rise may reflect disease progression and its expression might have been induced by an active necro-inflammatory process. In this regard, Kukla et al. (2009) reported that sPECAM-1 may influence VCAM-1 expression and concluded that $\mathrm{HCV}$ infection results in upregulation of both sPECAM-1 and sVCAM-1. The sPECAM-1 levels were related to necro-inflammatory activity and may be of value in identifying patients with advanced fibrosis.

During this transendothelial migration, the leukocyte squeezes in between two neighboring endothelial cells without disrupting the integrity of the endothelial barrier. For neutrophils, this is accomplished by homotypic binding of platelet endothelial cell adhesion molecule-1 (PECAM-1) on the neutrophil with PECAM-1 within the endothelial junction.

In the present work, there were numerical, but not statistically significant increases in AFP levels in the HCV patients as compared to the control individuals. On the contrary, a highly significant increase in serum AFP levels was found in the HCC and $\mathrm{HCV}+\mathrm{HCC}$ patients, in comparison with either the corresponding control or the HCV groups. These findings are in harmony with the results reported by Kumada et al. (2011) and Tateyama et al. (2011) which revealed that elevation of AFP was correlated with increased risks of HCC development in populations infected with $\mathrm{HCV}$. In this regard, Gomaa et al. (2009) reported that serum AFP was the most widely used biomarker of HCC. AFP is a fetal glycoprotein produced by the embryonic liver in utero cells of the yolk sac as well as the fetal intestinal tract and usually reaches a maximum level of about $3 \mathrm{~g} / \mathrm{L}$ at weeks 12 to 16 of fetal life. Thereafter, AFP levels diminish rapidly after birth and remain stable at a low level during adulthood (Debruyne et al., 2008). Sell (2008) showed 
Tarek Abdel Satter et al.

that serum AFP produced by HCC cells indicates that the tumor arises from hepatic stem cells as a form of maturation arrest, similar to an embryonic state. Bai et al. (2017) reported that the AFP level in diagnosis was an independent risk predictor associated with pathological grade, progression, and survival in patients with HCC. Approximately $50 \%$ of hepatocellular carcinoma cells secrete AFP and a plasma AFP concentration $>400 \mathrm{ng} / \mathrm{ml}$ is generally considered a reliable value for supporting the diagnosis of HCC (Song et al., 2016). However, the reliability the serum AFP concentration in HCC surveillance is still controversial and a matter of debate. It is worth mentioning that in the present study, only the AFP concentration of the female HCC patients exceeded $400 \mathrm{ng} / \mathrm{ml}$, whereas the male $\mathrm{HCC}$, male and female $\mathrm{HCV}+\mathrm{HCC}$ patients ranged between 316 and $366 \mathrm{ng} / \mathrm{ml}$. In this regard, Lee et al. (2013) suggested that screening algorithms for HCC patients should take into consideration data collected on the levels of AFP over time to identify patients most likely to develop hepatocellular carcinoma.

In the present study, serum caspase-3 activity was not significantly changed in the HCC patients, although there was a slight numerical decrease in comparison with the control or with the HCV groups. Over expression or loss of expression of caspase-3 has been reported in diverse human malignancies (Persad et al., 2004). Caspase3 belongs to IL-1 $\beta$ converting enzyme family, widely distributed in various cells in the body while its distribution and expression is different in different tissue. Its expression is more common in the cells with relatively strong metabolism. Under normal circumstances, the caspase-3 in cytoplasm exists as an inactive zymogene form of caspase-3, and only when apoptosis occurs, there is detectable active caspase-3 (Ding, 2010). It is possible that the determination of caspase- 3 activity in the serum, as it was the case in the present work, instead of the liver tissue could have masked any actual alteration that might have happened in the hepatic cells. It is logic to suggest that for the detection of a significant change in an intracellular enzyme such as caspase- 3 in the serum, the magnitude of change should be very high in the particular tissue which is supposed to be the source of the enzyme activity. Persad et al. (2004) reported that caspase-3 over expression was present in hepatoma cell lines, and its over expressed in HCCs was frequently associated with high serum levels of AFP.

Marquardt and Edlich(2019)reported that liver fibrogenesis and carcinogenesis are significantly accelerated by oxidative stress, cell death and inflammation. In chronic damage, apoptosis is activated by the mitochondrial or the intrinsic pathway which is regulated on the outer mitochondrial membrane (OMM) by B-cell lymphoma 2 (BCL-2) proteins. These authors postulated that hepatocyte death is a key driver of chronic inflammatory liver diseases and hepatocarcinogenesis.

It has been postulated that caspase-3 is a critical molecule for stimulating apoptosis in cancerand caspase- 3 is the main cleavage enzyme to promote apoptosis (Wang et al., 2019). It is a central executor of programmed cell death, while the caspase- 6 and caspase-7, the other two apoptotic executors, have been shown to compensate the functions of caspase- 3 in somecell contexts only (Shang et al., 2018). Accordingly, in chronic inflammation and liver damage, major cell death processes as well as signaling pathways are associated with liver cancer development and mainly involve both apoptosis and necrosis. However, several lines of evidence suggest that other forms of cell death, such as autophagy, necroptosis, pyroptosis, ferroptosis, or combinations of these death 


\section{Evaluation of VCAM-1 and SPCAM-1 as biomarkers for the detection of Hepatocellular Carcinoma in patients with Hepatitis $\mathrm{C}$ virus}

programs, are linked to HCC development and progression.

Huang et al., (2010) demonstrated that low expression of caspase- 3 is correlated with poor prognosis in $\mathrm{HCC}$ patients, suggesting that caspase- 3 might be involved in HCC pathogenesis. However, the role of caspase- 3 in HCC development in vivo has not been clearly reported.

In the present work, the statistical analyses revealed that there was a significant increase in monocyte chemoattractant protein-1 (MCP-1) in the HCC patients as compared to the control or to the $\mathrm{HCV}$ groups. Inflammatory chemokines are involved in the recruitment of effector leukocytes to the site of inflammation and they are frequently induced upon infection, inflammation, tissue injury, tumors or other stress factors (Crijns et al., 2020). MCP-1 is a member of the small inducible gene (SIG) family and is secreted in response to signals such as proinflammatory cytokines and may play a role in the recruitment of monocytes to sites of injury and infection. Once induced, the directed migration of cells from the bloodstream across the vascular endothelium expressing the appropriate chemokine receptors occurs along a chemical ligand gradient known as the chemokine gradient which is associated with HCC development. This allows cells to move toward high local concentrations of chemokines. In addition,Wanget al. (2013) identified serum MCP-1 as a promising and potentially complementary biomarker along with AFP and recommended that MCP1+AFP model should be further studied as a potential biomarker in patients at-risk of HCC.

In this regard, Dagouassat et al. (2009) showed liver myofibroblasts act on human hepatoma cells in a paracrine manner to promote the severity of their invasiveness and suggested that myofibroblast-derived
MCP-1/CCL2 could be an important player in the pathogenesis of hepatocellular carcinoma. Moreover, it was reported that the main source of the circulating MCP-1 is the injured liver cells and their level is corelated with severity of liver disease. Therefore, liver macrophages contribute significantly to disease progression and circulating MCP-1 may reflect the extent of hepatic macrophage activation (Queck et al., 2020).

For identifying an ideal diagnostic biomarker, it should have high sensitivity and specificity. To determine the sensitivity and specificity of biomarkers, the area under the curve (AUC) of a receiver operating characteristic (ROC) curve is measured in this study. A receiver operating characteristic curve is a graphical plot that illustrates the diagnostic ability of a binary classifier system as its discrimination threshold is varied. The ROC curve is created by plotting the true positive rate (TPR) against the false positive rate (FPR) at various threshold settings. The truepositive rate is designated as sensitivityrecall or probability of detection in machine learning. The false-positive rate is designated as probability of false alarm and can be calculated as (1- specificity) (MATLAB for Artificial Intelligence, 2016; www.mathworks.com).

Based on the ROC curve analysis, the optimal cut-off value of sPECAM was $102.5 \mathrm{ng} / \mathrm{ml}$ dependent on $\mathrm{HCV}$ positive values, with $\mathrm{AUC}=0.66$ with low sensitivity and specificity $68 \%$ and $68.9 \%$ respectively. While, we could not use sPECAM as indicator for HCC because of the low $\mathrm{AUC}=0.42$, therefore $\mathrm{sPECAM}$ was not able to discriminate between groups.Kukla et al. (2009) reported that AUC (0.81) concentration of SPECAM for detection of liver fibrosis at cut-off 221.0 $\mathrm{ng} / \mathrm{ml}$ (sensitivity $62.8 \%$ and specificity 
Tarek Abdel Satter et al.

$100 \%)$. While ROC curve showed AUC (0.78) in fibrosis stages $0-2$ versus stage 3 with cut-off set $237.1 \mathrm{ng} / \mathrm{ml}$ (sensitivity $77.7 \%$ and specificity $87.5 \%$ ).

The VCAM-1 also in the present study, failed to discriminate between groups because low of AUC $=0.52$ in both models. Therefore, this marker is not reliable for detection of $\mathrm{HCV}$ or HCC. The present result was in alignment with those of Kukla et al. (2009) who reported that there was no discriminant power of sVCAM-1 concentrations for liver fibrosis (stage 1 versus stage 2-3, with the same AUC 0.52, sensitivity $66 \%$ and specificity $50 \%$ ). In the present work, the evaluation of the usefulness of sVCAM-1 determination with respect to the differentiation of fibrosis stage by the assessment of area under the ROC curve for sVCAM-1 concentrations revealed negative results. Analysis of the area under ROC curveby Lo Iacono et al. (1998) were contrary to our findings when the cut-off point was set at $1280 \mathrm{ng} / \mathrm{ml}$, but these results were reliable for fibrosis/cirrhosis liver, but not HCC cases.

From the ROC curve, the cut-off value for serum casp-3 was $112.5 \mathrm{ng} / \mathrm{ml}$ in case of positive $\mathrm{HCV}$ as detected by PCR with good sensitivity and specificity (72\% and $73.3 \%$ ) respectively at $\mathrm{AUC}=0.744$. Therefore, casp-3, is considered as fair discriminative power for $\mathrm{HCV}$ in serum, but not in the hepatic tissue. Although this marker was not considered as a good discriminate for $\mathrm{HCC}$ with $\mathrm{AUC}=0.30$, but our study represents the first analysis with ROC curve for serum caspase- 3 .

In the present study, AFP reflected a good discriminative power for HCC prognosis at cut-off $163.5 \mathrm{ng} / \mathrm{ml}$ with $\mathrm{AUC}=0.777$ at $\mathrm{p}<0.001$ with high sensitivity and specificity (70\% and 100\%), respectively. More than one researcher reported cut-off for AFP at $200 \mathrm{ng} / \mathrm{ml}$ (Baghdady et al.2014, and Khattab et al.,
2015), whereas, a cut-off level at $400 \mathrm{ng} / \mathrm{ml}$ resulted in a lower sensitivity and specificity of 99\% (Trevisani et al., 2001). Song et al. (2016) considered a plasma AFP concentration $>400 \mathrm{ng} / \mathrm{ml}$ reliable for supporting the diagnosis of HCC. Chan et al. (2014) also considered a cut-off at 500 $\mathrm{ng} / \mathrm{ml}$ with $100 \%$ specificity and lower sensitivity as reliable. Morcos et al. (2012) found a cut-off at $64.7 \mathrm{ng} / \mathrm{ml}$ at sensitivity and specificity $(100 \%$ and $61 \%)$, respectively. Wang et al. (2013) and Tsuchiya et al. (2015) reported a cut-off at $20 \mathrm{ng} / \mathrm{ml}$. However, Chaiteerakij et al. (2015) reported $10.9 \mathrm{ng} / \mathrm{ml}$ as a cut-off of AFP. Wang et al. (2013) determined the value to be $4.0 \mathrm{ng} / \mathrm{ml}$, with $89.9 \%$ sensitivity and $92.7 \%$ specificity. However, results showed that AFP was not significant for HCV positive model.

In alignment with the present results, the European and Asian Pacific Guidelines recommended the use of AFP level at 200 $\mathrm{ng} / \mathrm{ml}$ as a reliable cut-off for HCC diagnosis (Omata et al.,2010). Also, in the same line of reasoning, AFP test should not be terminated from guidelines for $\mathrm{HCC}$ in Asian patients with suspicious liver lesion at cut-off $200 \mathrm{ng} / \mathrm{ml}$ (Chan et al., 2014). On the contrary, Carr et al. (2016) reported that not all HCC tumors secrete a large amount of AFP into the blood and not all tumors were positive for AFP determination. Therefore, Western Guidelines for Clinical Management of HCC eliminated AFP from the screening and surveillance because it was not sensitive enough to identify early stage of $\mathrm{HCC}$ and not specific enough to avoid unnecessary recall procedures (AISF, 2013). Also, the American Association for the Study of Liver Diseases (ASSLD) guidelines recommended this elimination (Bruix and Sherman, 2011). In addition, Fattovich et al. (2004) pointed out to another problem to drop AFP from HCC screening which embraces liver tissue already 


\section{Evaluation of VCAM-1 and SPCAM-1 as biomarkers for the detection of Hepatocellular Carcinoma in patients with Hepatitis $\mathrm{C}$ virus}

damaged by one or more preexisting pathologic conditions, including cirrhosis and chronic hepatitis viral infection. For these reasons, the parentage of the isoform of alpha-fetoprotein (AFP-L3) was considered more accurate and may be a predicator to differentiate HCC from chronic liver diseases when the total AFP level is equal to or more than $200 \mathrm{ng} / \mathrm{ml}$ (Leerapun et al., 2007). A total serum AFP above 200 $\mathrm{ng} / \mathrm{mL}$ is highly suggestive of a diagnosis of hepatocellular carcinoma when AFP-L3 results of $10 \%$ or above. This percentage of the L3 isoform or above are associated with a 7-fold increased risk of developing hepatocellular carcinoma according to Mayoclinc Laboratories Current Practice Guidelines

(mayocliniclabs.com/testcatalog/Clinical+and+Interpretive/88878).

In the present study, MCP-1 was significant for $\mathrm{HCC}$ with fair discriminative power and $\mathrm{AUC}=0.773$ at $\mathrm{p}<0.001$ with optimal cut-off value at $265 \mathrm{pg} / \mathrm{ml}$ with high sensitivity $96 \%$ and low specificity $64.3 \%$. Wang et al. (2013) found that cut-off at 390 $\mathrm{pg} / \mathrm{ml}$ with sensitivity $73.1 \%$ and $80.9 \%$ specificity and Galal and Raafat (2016) found that MCP-1 at a cut-off value $>0.390$ $\mathrm{ng} / \mathrm{ml}$ had a sensitivity of $75.8 \%$ and specificity of $88.3 \%$ with AUC $91.6 \%$ However, MCP-1 cannot be considered as indicator for $\mathrm{HCV}$ based on the results of ROC curve analysis undertaken in the present study..

The IL-6 did not have a good discriminative power for $\mathrm{HCV}$ or $\mathrm{HCC}$ because of low AUC (0.647 and 0.496) respectively as well as its low sensitivity $(78.7 \%$ and $64 \% \%)$ respectively and specificity $(51.1 \%$ and $51.4 \%)$. While Porta et al. (2008) reported that the cut-off of IL-6 reached $7.9 \mathrm{pg} / \mathrm{ml}$ with a sensitivity of $83 \%$, a specificity of $83 \%$, and an AUC of $81 \%$. Also, IL-10 was not sensitive for $\mathrm{HCV}$ or
HCC because of the low AUC (0.639 and 0.342 ) respectively.

The ROC curve analyses herein revealed that IL-8 was not an indicator for HCV because of the low AUC (0.526). On the contrary, the IL- 8 is considered a fair discriminative power for HCC with AUC $=0.764$ at optimal cut-off value of $189.5 \mathrm{pg} / \mathrm{ml}$, sensitivity $60 \%$ and highly specificity $88.6 \%$. The ROC curve results showed that $\mathrm{TNF}-\alpha$ is not a reliable marker for $\mathrm{HCV}$ because of having an AUC value of (0.533). Nonetheless, in the prognosis of HCC it's a fair discriminant power with AUC $=0.731$ at $p<0.001$ and a cut-off value that reached to $5.75 \mathrm{pg} / \mathrm{ml}$ with $86 \%$ sensitivity and $50 \%$ specificity. However, the INF- $\gamma$ was not found to be a good HCC marker as it had very low $\mathrm{AUC}=0.298$. But it may be considered as a fair indicator for $\mathrm{HCV}$ with an $\mathrm{AUC}=0.702$ at $\mathrm{p}<0.001$ with $65.2 \%$ sensitivity and $82.2 \%$ specificity with optimal cut-off value $102.5 \mathrm{pg} / \mathrm{ml}$.

In conclusion, relying on a single marker for the diagnosis of HCC is not possible by employing the nowadays widely used markers in diagnostic practice. Instead a signature of multiple biological markers is required to aid in this issue. The results based on the in-depth ROC analyses for each single one of these markers individually did not provide the proper combination of sufficient sensitivity and specificity required for conclusive diagnosis or prediction. The overall deduction of this study points strongly to the need for a new motif which includes a combination of multiple interacted biomarkers to increase the predictive accuracy of HCC diagnosis in cirrhotic patients. The suggested motif should comprise screening algorithms based on data collected on the levels of these biomarkers over time.

The present study also revealed that sPECAM and sVCAM, were not sensitive 
Tarek Abdel Satter et al.

indicators for $\mathrm{HCC}$ diagnosis because of their low discriminative power between groups. Consequently, they were passive with respect to their predictive power in progression of $\mathrm{HCV}$-related $\mathrm{HCC}$ development. However, these results may provide a new insight which shows the limitation of this line of research and sets aside these molecules in future investigations toward a novel antiangiogenic drug effective in the treatment of HCC.

\section{REFERENCES}

Abbas, Z. and Abbas, M. (2018). Factors predicting hepatocellular carcinoma in hepatitis $\mathrm{C}$ infection. Hepatoma Res., 4:43.

Abd El Moety, A. A. and Abd El Moety, H. (2011).Evaluation of nitric oxide as a novel diagnostic marker for hepatocellular carcinoma. Alex. J. Med. 47(1): 31-35.

Alqahtani, A.; Khan, Z.; Alloghbi, A.; Ahmed, T. S.; Ashraf, M. and Hammouda, D. M. (2019). Hepatocellular Carcinoma: Molecular Mechanisms and Targeted Therapies. Medicina, 55: 526.

Baghdady, I.; Fouada, F.; Sayed, M.; Shoaiba, A.; Salaha, Y.; Elshayeb, E. and Hasana, A. E. (2014). Serum markers for the early detection of hepatocellular carcinoma in patients with chronic viral hepatitis $\mathrm{C}$ infection. Menoufia Med. J. 27(3): 544-550.

Baghel, K.; Srivastava, R. N.; Chandra, A.; Goel, S. K.; Agrawal, J.; Kazmi, H. R. and Raj, S.(2014).TNF-a, IL-6, and IL-8 cytokines and their association with TNF- $\alpha-308 \mathrm{G} / \mathrm{A}$ polymorphism and postoperative sepsis. J. Gastrointest. Surg., 18(8):1486-1494.
Bai, D. S.; Zhang, C.; Chen, P.; Jin, S. J. and Jiang, G. Q. (2017). The prognosticcorrelation of AFP level at diagnosis with pathological grade, progression, and survival of patients with hepatocellular carcinoma. Scientific reports. 7(1), 1-9.

Balkwill, F. and Mantovani, A. (2001). Inflammation and cancer: back to Virchow. Lancet, 357(9255): 539545.

Balogh, J.; Victor III, D.; Asham, E. H.; Burroughs, G. S.; Boktour, M.; Saharia, A.; Li, X.; Ghobrial, R. M. and Monsour, H. P. (2016).Hepatocellular carcinoma: a review.J Hepatocell Carcinoma.3: $41-53$.

Baltimore, D. (2009).Discovering NF$\kappa$ B.Cold Spring Harb PerspectBiol.1(1):a000026.

Bansal, A.and Simon, M. C. (2018).Glutathione Metabolism in Cancer Progression and Treatment Resistance J Cell Biol.217(7):22912298.

Barreiro, O.; Yáñez-Mó, M.; Serrador, J. M.; Montoya, M. C.; VicenteManzanares, M.; Tejedor, R.; Furthmayr, H. and Sánchez-Madrid, F. (2002).Dynamic interaction of VCAM-1 and ICAM-1 with moesin and ezrin in a novel endothelial docking structure for adherent leukocytes.J Cell Biol. 157(7): 1233-1245.

Billiau, A. and Matthys, P. (2009). Interferon-gamma: A Historical Perspective. Cytokine Growth Factor Rev. 20(2): 97-113

Bruix, J. and Sherman, M. (2011). Management of hepatocellular carcinoma: an update. Hepatology 53(3):1020-1022. 
Bruno, C. M.;Sciacca, C.;Cilio, D.;Bertino, G.; Marchese, A. E.;Gaetana Politi, G. and Chinnici, L. (2005). Circulating adhesion molecules in patients with virus-related chronic diseases of the liver.World $\mathbf{J}$ Gastroenterol. 7; 11(29): 45664569.

Budhu, A. and Wang, X. (2006). The role of cytokines in hepatocellular carcinoma.Journal of Leukocyte BiologyVolume 80, December. Journal of Leukocyte Biology, 80(6):1197-1213.

Burkholder, B.;Huang, R. Y.;Burgess, R.;Luo, S.;Jones, V. S.;Zhang, W.;Lv, Z. Q.;Gao, C. Y.;Wang, B. L.;Zhang, Y. M. and Huang, R. P.(2014).Tumor-induced perturbations of cytokines and immune cell networks.Biochimica et Biophysica Acta (BBA) - Reviews on CancerVolume 1845(2):182-201.

Byrne, G. J.; Ghellal, A.; Iddon, J.; Blann, A. D.; Venizelos, V.; Kumar, S.; Howell, A. and Bundred, N. J.(2000).Serum soluble vascular cell adhesion molecule-1: role as a surrogate marker of angiogenesis. $\mathbf{J}$ Natl Cancer Inst. 92(16): 13291336.

Cai, H.; Zhang, Y.; Meng, F.; Cui, C.; Li, H.; Sui, M.; Zhang, H. and Lu, C. (2019). Preoperative Serum IL6, IL8, and TNF- $\alpha$ May Predict the Recurrence of Hepatocellular Cancer. Gastroent Res Pract.,ID 6160783.

Capece, D.; Fischietti, M.; Verzella, D.; Gaggiano, A.; Cicciarelli, G.; Tessitore, A.; Zazzeroni, F. and Alesse, E. (2013). The Inflammatory Microenvironment in Hepatocellular Carcinoma: A Pivotal Role for Tumor-Associated
Macrophages. Biomed Res. Int.,ID 187204.

Carr B. I. and Guerra, V. (2016).Low AlphaFetoprotein Levels Are Associated with Improved Survival in Hepatocellular Carcinoma Patients with Portal Vein Thrombosis. Dig. Dis. Sci. 61(3):937-947. Chaiteerakij, R.; Addissie, B. D. and Roberts, L. R. (2015). Update on Biomarkers of Hepatocellular Carcinoma. Clin.Gastroenterol.Hepatol.13(2):23 7-245.

Chan, D. W. and Miao, Y. C. (1986).Affinity chromatographic separation of alpha-fetoprotein variants: Development of a minicolumn procedure and application to cancer patients. Clin Chem. 32(12):2143-2146.

Chan, S. L.; Mo, F.; Johnson, P. J.; Siu, D. Y. W.; Chan, M. H. M.; Lau, W. Y.; Lai, P. B. S.; Lam, C.W.; Yeo, W. and $\mathrm{Yu}, \quad \mathrm{S}$. C. $\mathrm{H}$. (2014).Performance of serum $\alpha$ fetoprotein levels in the diagnosis of hepatocellular carcinoma in patients with a hepatic mass.HPB.16(4): 366-372.

Crijns, H.; Vanheule, V. and Proost, P. (2020). Targetin ChemokineGlycosaminoglycan Interactions to Inhibit Inflammation. Front. Immunol., 11:483.

Dagouassat, M.; Suffee, N.; Hlawaty, H.; Haddad, O.; Charni, F.; Laguillier, C.; Vassy, R.; Martin, L. A.; Schischmanoff, P.O.; Gattegno, L.; Oudar. O.; Sutton, A. and Charnaux, N. (2010): Monocyte chemoattractant protein-1 (MCP1)/CCL2 secreted by hepatic myofibroblasts promotes migration and invasion of human hepatoma 
Tarek Abdel Satter et al.

cells. Int. J. Cancer, 126(5):10951108.

Dandachi, D.; Hassan, M.; Kaseb, A.; Angelidakis, G. and Torres, H. A. (2018). Hepatitis C virus-associated hepatocellular carcinoma as a second primary malignancy: exposing an overlooked presentation of liver cancer. J Hepatocell Carcinoma. 5:81-86.

De Castro, I. F.; Micheloud, D.; Berenguer, J.; Guzmán-Fulgencio, M.; Catalán, P.; Miralles, P.; Álvarez, E.; López, J. C.; Cosín, J.; Lorente, R.; Muñoz-Fernández, M. Á. and Resino, S. (2010). Hepatitis C virus infection is associated with endothelial dysfunction in HIV/hepatitis C virus coinfected patients. Aids, 24(13):2059-2067.

Debruyne, E. N. and Delanghe, J. R. (2008). Diagnosing and monitoring hepatocellular carcinoma with alpha-fetoprotein: new aspects and applications. Clin Chim Acta., 395(1-2): 19-26.

Detector Performance Analysis Using ROC Curves - MATLAB \& Simulink Example".www.mathworks.com.

Retrieved 11 August 2016.

Deuffic-Burbana, S.; Mohamed, M. K.; Larouze, B.; Carrat, F. and Valleron, A. J. (2006). Expected increase in hepatitis C-related mortality in Egypt due to pre-2000 infections J. Hepatol., 44(3):455-461.

Di -Bisceglie, A. M.; Lyra, A. C.; Schwartz, M.; Reddy, R. K.; Martin, P.; Gores, G.; Lok, A. S. F.; Hussain, K. B.; Gish, R.; Thiel, D. V. H.; Younossi, Z.; Tong, M.; Hassanein, T.; Balart, L.; Fleckenstein, J.; Flamm, S.; Blei, A.; Befele, A. S. and Liver Cancer Network (2003). Hepatitis C-related hepatocellular carcinoma in the United States: influence of ethnic status. The American Journal of Gastroenterology. 98(9): 2060-2063. Diaz-Sanchez, A.; Matilla, A.; Nuñez, O.; Rincon, D.; Lorente, R.; Lo Iacono, O.; Merino, B.; Hernando, A.; Campos, R.; Gerardo Clemente, G. and Bañares, R. (2013).Serum level of soluble vascular cell adhesion molecule in patients with hepatocellular carcinoma and its association with severity of liver disease.Annals Hepatology, 12(2): 236-247.

Ding, W.; Hu, W.; Wang, X. and Dong, X. (2010). Expressions of Survivin and Caspase-3 in human hepatocellular carcinoma and the relationship with prognosis Chinese-German J Clin Oncol, 9(11): 628-632.

Dudakov, J. A; Hanash, A. M. and van den Brink, M. R. M. (2015). Interleukin22: immunobiology and pathology. Annu Rev Immunol, 33:747-785.

Eissa, L. A.; Eisa, N. H.; Ebrahim, M. A.; Ragab, M. and El-Gayar, A. M. (2013). Nitric Oxide is a Potential Diagnostic Marker for Hepatocellular Carcinoma. Sci Pharm. 81: 763-775.

Fallahi, P.; Ferri, C.; Ferrari, S. M.; Corrado, A.; Sansonno, D. and Antonelli, A. (2012).Cytokines and HCV-Related Disorders. Clin. Exp. Immunol. Article ID 468107 , doi:10.1155/2012/468107

Fattovich, G.; Stroffolini, T.; Zagni, I. and Donato, F. (2004).Hepatocellular carcinoma in cirrhosis: incidence and risk factors. Gastroenterology. 127(1):S35-S50.

Fischer, J. E; Bachmann, L. M. and Jaeschke, R. (2003).A readers guide to the interpretation of diagnostic test properties: Clinical example of sepsis. Intensive Care Med 29(7): 1043-1051. 
Galal, S. M. and Raafat, N. (2016).Monocyte Chemoattractant Protein-1 as a Diagnostic Marker for Detection of Hepatocellular Carcinoma in Egypt. Afro-Egypt $\mathrm{J}$ Infect Endem Dis. 6(2): 75-81.

Ghafar, A. A.; Ghoneem, E.; Rozaik, S.; Akef, A. and Mortada, M. (2019).Prognostic value of interleukin-10 and tumor necrosis factor- $\alpha$ polymorphisms in patients with hepatocellular carcinoma treated with transarterial chemoembolization The Egyptian Journal of Internal Medicine, 31(3):254-260.

Gomaa, A. I.; Khan, S. A.; Leen, E. L.; Waked, I. and Taylor-Robinson, S. D. (2009).Diagnosis of hepatocellular carcinoma.World J Gastroenterol. 15(11): 1301-1314.

Govender, D.; Harilal, P.; Dada, M. and Chetty, R. (1997).CD31 (JC70) expression in plasma cells: an immunohistochemical analysis of reactive and neoplastic plasma cells. J Clin Pathol. 50(6): 490-493.

Grivennikov, S. I.; Greten, F. R. and Karin, M. (2010).Immunity, Inflammation and Cancer. Cell, 19; 140(6): 883899.

He, G. and Karin, M. (2011).NF-kB and STAT3 - key players in liver inflammation and cancer.Cell Research. 21(1):159-168.

Hintermann, E. and Christen, U. (2019). The Many Roles of Cell Adhesion Molecules in Hepatic Fibrosis.Cells.8(12):1503.

Holz, L. andRehermann, B. (2015). T Cell Responses in Hepatitis C Virus Infection: Historical Overview and Goals for Future Research.Antiviral Res.; 114: 96-105.
Hu, X. M.; Hirano, T. and Oka, K. (2003).Arsenic trioxide induces apoptosis in cells of MOLT-4 and its daunorubicin-resistant cell line via depletion of intracellular glutathione, disruption of mitochondrial membrane potential and activation of caspase-3. Cancer Chemother.Pharmacol. 52(1):47-58.

Huang, H.; Zhang, X. F.; Zhou, H. J.; Xue ,Y. H.,;Dong, Q.; Ye, Q. H. and Qin, L. X. (2010).Expression and prognostic significance of osteopontin and caspase- 3 in hepatocellular carcinoma patients after curative resection. Cancer Sci., 101(5): 1314-1319.

Iacono, L.; Garcia-Monzon, O.; Almasio, C.; Garc1'a-Buey, P.; Craxı', L. and Moreno-Otero, R. (1998). Soluble adhesion molecules correlate with liver inflammation and fibrosis in chronic hepatitis $\mathrm{C}$ treated with interferon. Aliment Pharmacol Ther 12(11): 1091-1099.

Italian Association for the Study of the Liver (AISF); AISF Expert Panel; AISF Coordinating Committee.(2013)Position paper of the Italian Association for the Study of the Liver (AISF): the multidisciplinary clinical approach to hepatocellular carcinoma. Dig Liver Dis.45:712-723.

Jekarl, D.W.; Lee, S.; Kwon, J. H.; Nam, S. W.; Kim, M.; Kim, Y. and Jang, J. W. (2019). Complex interaction networks of cytokines after transarterial chemotherapy in patients with hepatocellular carcinoma. PLoS ONE 14(11).

Jie, Y. Z.; Qiang, J.U. and Guan-Cheng, L. I. (2013).Tumor markers for hepatocellular carcinoma.Molecular 
Tarek Abdel Satter et al.

and clinical oncology, 1(4): 593598.

Jung, H. and Miller, R. J. (2008). Activation of the nuclear factor of activated $\mathrm{T}$ cells (NFAT) mediates upregulation of CCR2 chemokine receptors in dorsal root ganglion (DRG) neurons: A possible mechanism for activity-dependent transcription in DRG neurons in association with neuropathic pain. Mol Cell Neurosci 37(1):170-177.

Karimi, M; Goldie, L. C; Cruickshank, M. N; Moses, E. K. and Abraham L. J. (2009). A critical assessment of the factors affecting reporter gene assays for promoter SNP function: a reassessment of -308 TNF polymorphism function using a novel integrated reporter system. Eur J Hum Genet; 17(11):14541462.

Katz, S. C.; Pillarisetty, V. G.; Bleier, J. I.; Shah, A. B. and De Matteo, R. P. (2004). Liver sinusoidal endothelial cells are insufficient to activate $\mathrm{T}$ cells.J Immunol.173(1):230-235.

Khattab, M.; Fouad, M. and Ahmed, E. (2015).Role of biomarkers in the prediction and diagnosis of hepatocellular carcinoma. World J Hepatol.,7(23): 2474-2481.

Kukla, M.; Zwirska-Korczala, K.; Gabriel, A.; Janczewska-Kazek, E.; Berdowska, A.; Wiczkowski, A.; Rybus-Kalinowska, B.; Kalinowski, M.; Ziolkowski, A.;WozniakGrygiel, E.; Waluga, M. and Nowak. B. (2009).sPECAM-1 and sVCAM-1: role in pathogenesis and diagnosis of chronic hepatitis $\mathrm{C}$ and association with response to antiviral therapy Therapeutic Advances in Gastroenterology, 2(2): 79-90.
Kumada, T.; Toyoda, H.;Kiriyama, S.;Tanikawa, M.;Hisanaga, Y.; Kanamori, A.;Tada, T.;Tanaka, J. and Hiroshi Yoshizawa, H. (2011). Predictive value of tumor markers for hepatocarcinogenesis in patients with hepatitis $\mathrm{C}$ virus. J Gastroenterol.,46(4):536-544.

Kumar, S. (2007). Caspase function in programmed cell death.Cell Death and Differentiation. 14(1): 32-43.

Larrubia, J. R.; Benito-Martínez, S.; Calvino, M.; Sanz de-Villalobos ;E. and Parra-Cid, T. (2008). Role of chemokines and their receptors in viral persistence and liver damage during chronic hepatitis $\mathrm{C}$ virus infection. World J Gastroenterol, 14(47): 7149-7159.

Lee, E.; Edward, S.; Singal, A. G. and Lavieri, M. S. (2013). Volk M. Improving screening for hepatocellular carcinoma by incorporating data on levels of $\alpha$ fetoprotein, over time.Clin Gastroenterol Hepatol.,11(4):437440.

Leerapun, A.; Suravarapu, S. V.; Bida, J. P.; Clark, R. J.; Sanders, E. L.; Mettler, T. A.;Stadheim, L. M.; Aderca, I.; Moser, C. D.; Nagorney, D. M.; LaRusso, N. F.; de Groen, P. C.; Menon K. V. N.; Lazaridis, K. N.; Gores, G. J.; Charlton, M. R.; Roberts, R. O.; Therneau, T. M.; Katzmann, J. A. and Roberts L. R. (2007). The utility of afp-13\% in the diagnosis of hepatocellular carcinoma: evaluation in a U.S. referral population. Clin Gastroenterol Hepatol., 5(3): 394267.

Liaw, Y.; Sung, J. J. Y. Chow, W. C.; Farrell, G.; Lee, C.; Yuen, H.; Tanwandee, T.; Tao, Q.; Shue, K.; Keene, O. N.; Dixon, J. S.; Gray, F. 
Evaluation of VCAM-1 and SPCAM-1 as biomarkers for the detection of Hepatocellular Carcinoma in patients with Hepatitis $\mathrm{C}$ virus

and Sabbat, J. (2004). Lamivudine for Patients with Chronic Hepatitis $\mathrm{B}$ and Advanced Liver Disease. N Engl. J. Med., 351(15):1521-1531.

Liu, C.; Li, L.; Lu, W. S.; Du, H.; Yan, L.; Wen, T. and Wei, W. R. (2018).A novel combined systemic inflammation based score can predict survival of intermediate-toadvanced hepatocellular carcinoma patients undergoing ransarterial chemoembolization. BMC Cancer, 18(1):216-225.

Lou, J.; Zhang, L.; Lv, S.; Zhang, C. and Jiang, S. (2017).Biomarkers for Hepatocellular Carcinoma. Biomarkers in Cancer, (9):1-9.

Madill, J.; Arendt, B.; Aghdassi, E.; Chow, C.; Guindi, M.; Therapondos, G.; Lilly, L.and Allard, J. (2010). Liver transplantation Outcome Oxidative Stress and Nutritional Factors in Hepatitis C Virus - Positive Liver Recipients, Controls, and Hepatitis C Virus-Positive Nontransplant Patients. Transplant Proc., 42(5): 1744-1749.

Marquardt, J. U.and Edlich.F. (2019).Predisposition to Apoptosis in Hepatocellular Carcinoma: From Mechanistic Insights to Therapeutic Strategies. Front Oncol, 9: 1421.

Marra, M.; Sordelli, I. M.; Lombardi, A.; Lamberti, M.; Tarantino, L.; Giudice, A.; Stiuso, P.; Abbruzzese, A.; Sperlongano, R.; Accardo, M.;Agresti, M.; Caraglia, M. and Sperlongano, P. (2011). Molecular targets and oxidative stress biomarkers in hepatocellular carcinoma: an overview. Journal of Translational Medicine, 9(1):171.

Miles, A. M.; Wink, D. A.; Cook, J. C. and Grisham, M. B.(1996). Determinationof nitric oxide using fluorescence spectroscopy. Methods Enzymol., 268:105-120.

Morcos, N. Y. S.; Khafagi, E. Z. I.; Mogawer, M. S.; Ali, M. M. and Abdel-Halim, A. H. (2012). Evaluation of biomarkers for the detection of hepatocellular carcinoma in patients with hepatitis C virus. J. Exp. Integr. Med., 2(4): 321-329.

Nakagawa, H. and Maeda, S. (2012).Inflammation-and stressrelated signaling pathways in hepatocarcinogenesis. World J Gastroenterol.,18(31):4071-4081.

National Comprehensive Cancer Network (2017). NCCN Clinical Practice Guidelines in Oncology. Hepatobiliary Cancers. Version 3.

Naugler, W. E. and M. Karin (2008). The Wolf in Sheep's Clothing: The Role of interleukin-6 in Immunity, Inflammation and Cancer Trends Mol. Med., 14(3):109-119.

Omata, M.; Lesmana, L. A.; Tateishi, R.; Chen, P. J.; Lin, S. M.; Yoshida, H.; Kudo, M.; Lee, J. M.; Choi, B. I.; Poon, R. T. P.; Shiina, S.; Cheng, A. L.; Jia, J. D.; Obi, S.; Han, K. H.; Jafri, W.; Chow, P.; Lim, S. G.; Chawla, Y. K.; Budihusodo, U.; Gani, R. A.; Lesmana, C. R.; Putranto, T. A.; Liaw, Y. F. and Sarin, S. K. (2010). Association of human platelet antigens polymorphisms with susceptibility to hepatitis $\mathrm{C}$ virus infection in Chinese population Asian Pacific Association for the Study of the Liver consensus recommendations on hepatocellular carcinoma. Hepatol. Int., 4(2):439-474.

Persad, R.; Liu, C.; Tsung-The, W.; Houlihan, P. S.; Hamilton, S. R.; Diehl, A. M. and Rashid, A. 
Tarek Abdel Satter et al.

(2004).Overexpression of caspase-3 in hepatocellular carcinomas Modern Pathol.,17(7): 861-867.

Pikarsky, E.; Porat, R. M.; Stein, I.; Abramovitch, R.; Amit, S.; Kasem, S.; Gutkovich, P. E.; Urieli, S.S.;

Galun, E. and Ben-Neriah, Y. (2004). NFkappaB functions as a tumour promoter in inflammation associated cancer. Nature, 431(7007): 461466.

Porta, C; De Amici, M.; Quaglini, S.; Paglino, C.; Tagliani, F.; Boncimino, A.; Moratti, R. and Corazza, G.R. (2008).Circulating interleukin-6 as a tumor marker for hepatocellular carcinoma. Ann Oncol., 19(2):353-358.

Queck, A.;Bode, H.; Uschner, F. E.; Brol, M. J.; Graf, C.; Schulz, M.; Jansen, C.; Praktiknjo, M.; Schierwagen, R.; Klein, S.; Trautwein, C; Wasmuth, H. E.; Berres, M.L.; Trebicka, J. and Lehmann, J. (2020). Systemic MCP1 Levels Derive Mainly From Injured Liver and Are Associated With Complications in Cirrhosis. Front. Immunol., 11: 354.

Ragab, G. and Hussein, M. A. (2017). Vasculitic syndromes in hepatitis $\mathrm{C}$ virus: A review. J Adv Res., 8(2): 99-111.

Salek-Ardakani, S. and Croft, M. (2010). Tumor Necrosis Factor Receptor/Tumor Necrosis Factor Family Members in Antiviral CD8 T-cell Immunity. J. Interferon Cytokine Res. 30(4):205-18.

Sell, S. (2008). Alpha-fetoprotein, stem cells and cancer: how study of the production of alpha-fetoprotein during chemical hepatocarcinogenesis led to reaffirmation of the stem cell theory of cancer. Tumor Biol., 29(3): 161-180.
Shang, N.; Bank, T.; Ding, X.; Breslin, P.; Li, J.; Shi, B. and Qiu, W. (2018). Caspase-3 suppresses diethyl nitrosamine induced hepatocyte death, compensatory proliferation and hepatocarcinogenesis through inhibiting p38 activation Cell Death and Disease, 9(5):558:1-11.

Sharma, M. (2010). Chemokines and their receptors: orchestrating a fine balance between health and disease Crit. Rev. Biotechnol., 30(1):1-22.

Song, P.P.; Xia, J.F.; Inagaki, Y.; Hasegawa,K.; Sakamoto, Y.; Kokudo, N. and Tang, W. (2016).Controversies regarding and perspectives on clinical utility of biomarkers in hepatocellular carcinoma. World J Gastroenterol., 22(1):262-274.

Subramaniam, S.; Kelley, R. K. and Venook, A. P. (2013).A review of hepatocellular carcinoma (HCC) staging systems Chin Clin Oncol., 2(4):33.1-12.

Takaki, A. and Yamamoto, K. (2015). Control of oxidative stress in hepatocellular carcinoma: Helpful or harmful? World J. Hepatol., 7(7): 968-979.

Tateyama, M.; Yatsuhashi, H.; Taura, N.; Motoyoshi, Y.; Nagaoka, S.;Yanagi, K.; Abiru, S.; Yano, K.;Komori, A.; Migita, K.; Nakamura, M.; Nagahama, H.;Sasaki, Y.; Miyakawa, Y. and Ishibashi, $\mathrm{H}$. (2011). Alpha-fetoprotein above normal levels as a risk factor for the development of hepatocellular carcinoma in patients infected with hepatitis C virus. J. Gastroenterol., 46(1):92-100. 


\section{Evaluation of VCAM-1 and SPCAM-1 as biomarkers for the detection of Hepatocellular Carcinoma in patients with Hepatitis $\mathrm{C}$ virus}

Thornberry, N. A. and Lazebnik,Y. (1998).Caspases: Enemies within Science. 281(5381):1312-1316.

Tousoulis, D.; Kampoli, A. M.; Tentolouris, C.; Papageorgiou, N. and Stefanadis, C. (2012).The role of nitric oxide on endothelial function. Curr Vasc Pharmacol., 10 (1):4-18.

Trevisani, F.; D'Intino, P.E.; MorselliLabate, A.M.; Mazzella, G.; Accogli, E.; Caraceni, P.; Domenicali, M.; De Notariis, S.; Roda, E. and Bernardi, M. (2001). Serum $\alpha$-fetoprotein for diagnosis of hepatocellular carcinoma in patients with chronic liver disease: influence of HBsAg and anti-HCV status. J Hepatol., 34(4): 570-575.

Tsuchiya, N.; Sawada, Y.; Endo, I.; Saito, K.; Uemura, Y. and Nakatsura; T. (2015).Biomarkers for the early diagnosis of hepatocellular carcinoma.World J. Gastroenterol., 21(37): 10573-10583.

Tsuchiya, N.; Sawada, Y.; Endo, I.; Saito, K.; Uemura, Y. and Nakatsura, T. (2015). Biomarkers for the early diagnosis of hepatocellular carcinoma.World J. Gastroenterol., 21(37): 10573-10583.

Vikram, N. K.; Bhatt. S. P.; Bhushan, B.; Luthra, K.; Misra, A.; Poddar, P. K.; Pandey, R.M. and Guleria, R. (2011). Associations of -308G/A polymorphism of tumor necrosis factor (TNF)-? Gene and serum TNF-?Levels with measures of obesity, intra-abdominal and subcutaneous abdominal fat, subclinical inflammation and insulin resistance in Asian Indians in north India. Dis Markers 31(1):39-46.

Wang, W. W.; Ang, S. F.; Kumar, R.; Heah, C.; Utama, A.; Tania, N. P.; Li, H.; Tan, S. H.; Poo, D.; Choo, S. P.;
Chow, W. C.; Tan, C. K. and Toh, H. C. (2013). Identification of Serum Monocyte Chemoattractant Protein-1 and Prolactin as Potential Tumor Markers in Hepatocellular Carcinoma, 8(7):1-10.

Wang, W.; Zhu, M.; Xu, Z.; Li, W.; Dong, X.; Chen, Y.; Lin, B. and Li, M. (2019). Ropivacaine promotes apoptosis of hepatocellular carcinoma cells through damaging mitochondria and activating caspase-3 activity. Biol. Res., 52(1): 36.

Wang, Z.; Li, Z.; Ye, Y.; Xie, L. and Li, W. (2016). Oxidative Stress and Liver Cancer: Etiology and Therapeutic Targets Oxidative. Oxid Med. Cell Longev. ID 7891574

Welling, T. H.; Fu, S.; Wan, S.; Zou, W. and Marrero, J. A. (2012). Elevated Serum IL-8 Is Associated With the Presence of Hepatocellular Carcinoma and Independently Predicts Survival. Cancer Invest., 30(10):689-697.

Wong, G.; Wong, V.; Choi, P.; Chan, A.; Chim, A.; Yiu, K.; Chan, F.; Sung, J. and Chan, H. (2009). Increased liver stiffness measurement by transient elastography in severe acute exacerbation of chronic hepatitis B. J. Gastroenterol., Hepatol., 24:1002-1007.

Yao, M.; Brummer,G.; Acevedo, D. and Cheng, N. (2016). Cytokine Regulation of Metastasis and Tumorigenicity. Adv. Cancer Res., 132(8).265-367.

Zekri, A. N.; Bahnassy, A. A.; Hafez, M. M.; Hassan, Z. K.; Kamel, M.; Loutfy, S. A.; Sherif, G. M., ElZayadi, A. and Daoud, S. S. (2011). Characterization of chronic $\mathrm{HCV}$ 
Tarek Abdel Satter et al.

infection-induced apoptosis. Comp. Hepatol., 10(1):4:1-14.

Zekri, A. R.; Ashour, M. S.; Hassan, A.; Alam El-Din, H. M.; El Shehaby, A. M. and Abu-Shady, M. A. (2005). Cytokine profile in Egyptian hepatitis $\mathrm{C}$ virus genotype-4 in relation to liver disease progression.World J. Gastroenterol., 11(42): 6624-6630.
Zhang, X.; Zhang, G.;Jiang, Y.;Liu, D.;Li, M.;Zhong, Q.; Zeng, S., Liu, W. and Zeng, M. (2015). The prognostic value of serum C-reactive proteinbound serum amyloid A in earlystage lung cancer. Chin. J. Cancer, 34(3):39:1-15.

تقييم VCAM-1 و SPCAM-1 كمؤشرات بيولوجية للكشف عن سرطان الخلايا الكبدية في المرضى المصابين بفيروس التهاب الكبا الوبائي سني سني

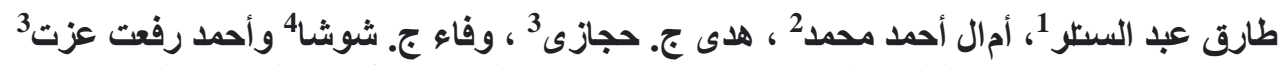

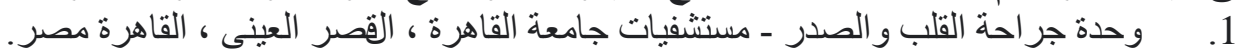

2.

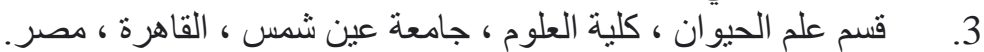

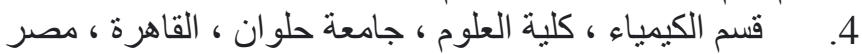

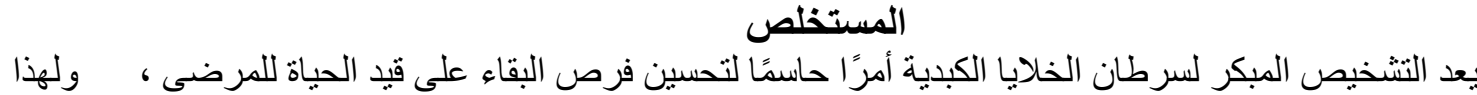

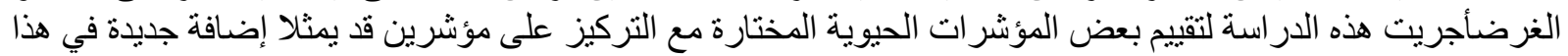

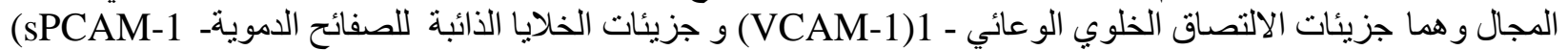

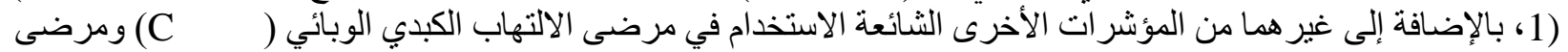

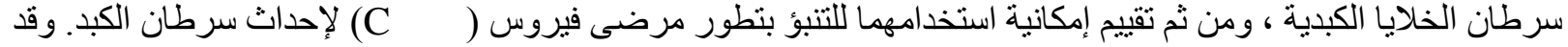

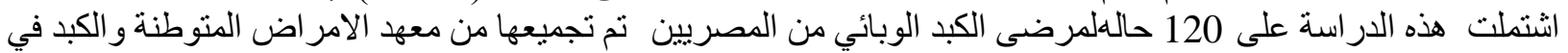

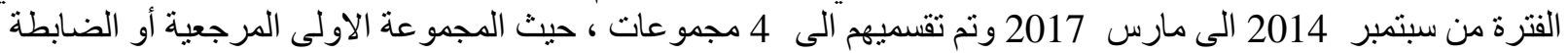

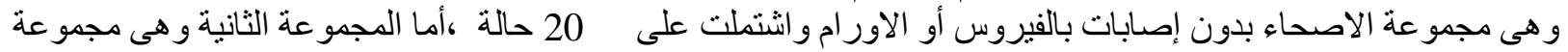

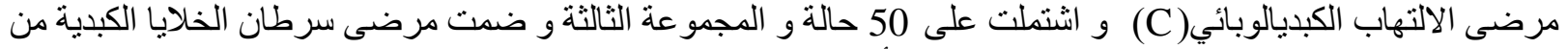

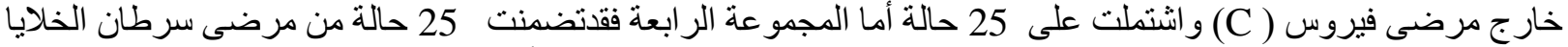

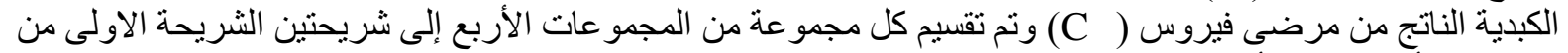

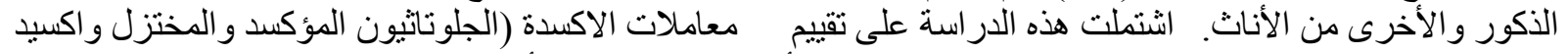

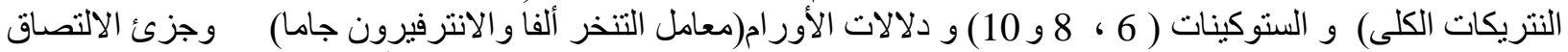

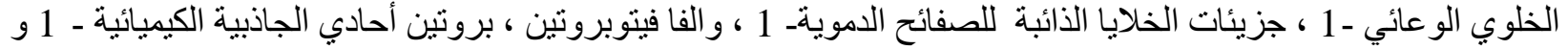

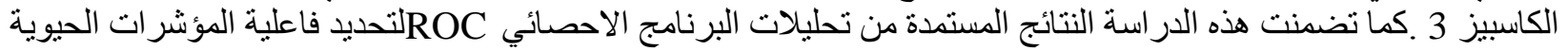

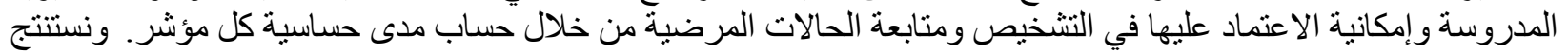

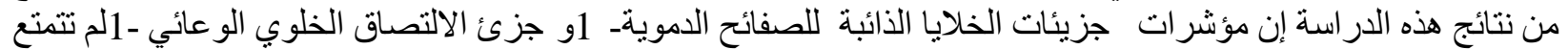

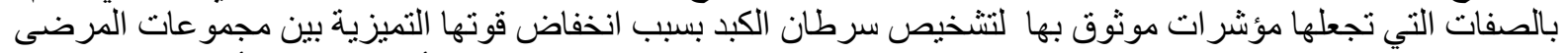

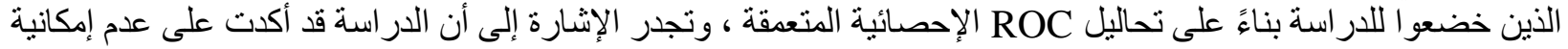

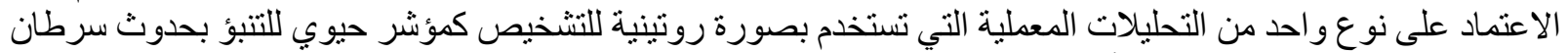

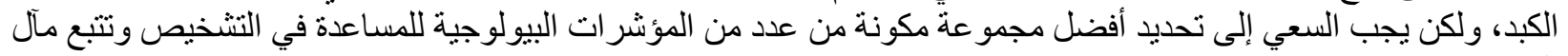

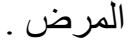

